Roger Williams University

DOCS@RWU

Summer 8-2009

\title{
Understanding Perceptions of Hypnotically Recovered Memories in a Civil Sexual Abuse Case
}

Samantha Fusco

RogerWilliams University, sfusco036@g.rwu.edu

Follow this and additional works at: https://docs.rwu.edu/psych_thesis

Part of the Psychology Commons

\section{Recommended Citation}

Fusco, Samantha, "Understanding Perceptions of Hypnotically Recovered Memories in a Civil Sexual Abuse Case" (2009). Psychology Theses. 4.

https://docs.rwu.edu/psych_thesis/4

This Dissertation is brought to you for free and open access by the Arts and Sciences Theses at DOCS@RWU. It has been accepted for inclusion in Psychology Theses by an authorized administrator of DOCS@RWU. For more information, please contact mwu@rwu.edu. 


\title{
Running head: RECOVERED MEMORIES IN CIVIL SEXUAL ABUSE
}

\author{
Understanding Perceptions of Hypnotically Recovered Memories \\ in a Civil Sexual Abuse Case \\ Samantha Fusco \\ Master of Arts \\ Forensic Psychology \\ Feinstein College of Arts and Sciences \\ Roger Williams University
}

August 2009 


\begin{abstract}
Perceptions of hypnosis and hypnotically recovered testimony were examined in a civil sexual abuse case. One hundred eighty-eight undergraduate students read one of eight trial transcript summaries varying expert witness testimony and victim testimony regarding the use of hypnosis in recovering a repressed memory of sexual abuse. We hypothesized that expert testimony would moderate the relation between victim testimony and perceptions of hypnotically recovered memory. In addition, we expected attitudes towards hypnotically refreshed memories would predict perceptions of the victim. Results found testimony elicited under hypnosis to be less accurate, less credible, and less believable than testimony not elicited from hypnosis. Results imply jurors' awareness and uncertainty of the use of hypnosis in this context.
\end{abstract}




\section{Table of Contents}

Abstract............................................................. ii

List of Tables..................................................... iv

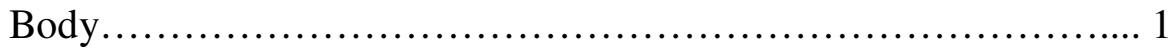

References.............................................................. 28

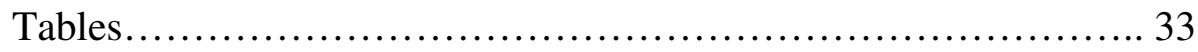

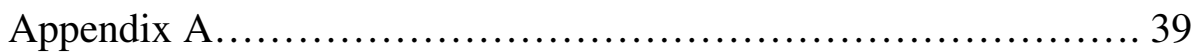


List of Tables

Table 1. Mean Responses to Survey Questions Clustered within Subscales

- Page 33 -

Table 2. Summary of MRA for Variables Predicting Defendant Liability

- Page 35 -

Table 3. Summary of MRA for Variables Predicting Accuracy of Plaintiff's Testimony

- Page 36 -

Table 4. Summary of MRA for Variable Predicting Believability of Plaintiff's Testimony

- Page 37 -

Table 5. Summary of MRA for Variable Predicting Credibility of Plaintiff's Testimony

- Page 38 - 
Understanding Perceptions of Hypnotically Recovered Memories in a Civil Sexual Abuse Case

In 1958, the American Medical Association defined hypnosis as, "a temporary condition of altered attention in the subject which may be induced by another person and in which a variety of phenomenon may appear spontaneously or in response to verbal or other stimuli" (as cited in Webert, 2003; p. 1301). These phenomena can include changes in awareness and memory, amplified vulnerability to suggestion, and the creation in the subject of reactions and thoughts foreign to him or her in their normal state of mind. Regardless of the purpose of hypnosis, the admissibility of a witness' hypnotically refreshed or recalled memories in court proceedings has been the subject of much controversy (Colwick, 1995). Many courts exclude all hypnotically enhanced testimony based upon the belief that hypnosis is inherently unreliable as a means of eliciting accurate memory. Others have ruled that hypnosis affects the weight rather than the admissibility of the testimony, thereby leaving the reliability issue to the jury. Overall, however, decisions regarding the admissibility of hypnotically refreshed and recalled memories vary by jurisdiction and case-specific circumstances (Webert, 2003).

\section{The Debate}

Researchers, practitioners, and law professionals arguing against the use of hypnosis in legal contexts identify three general problems concerning the reliability of hypnotically refreshed testimony. First, a person undergoing hypnosis may become more susceptible to suggestion, which can be an unconscious influence on his or her beliefs or attitudes. Thus, the subject may be influenced by both verbal and non-verbal cues planted by the hypnotist, either intentionally or unintentionally. Suggestibility may be enhanced 
by the perception that hypnosis will refresh one's memory or the need to please the hypnotist. Second, critics of hypnosis believe a hypnotized person may be more prone to confabulation; i.e., filling in memory gaps with additional details in order to make the memory more understandable. These additional details may be immaterial, dissimilar, or imagined facts that the hypnotized person believes to be true. The final issue is the belief that hypnosis produces memory hardening, a phenomenon that gives the subject enhanced confidence in the facts remembered, whether the facts are accurate or artificial. In addition, the hypnotized person may also experience source amnesia, which prevents them from identifying whether a memory occurred before or during hypnosis, or whether the memory is real or suggested. As a result, subjects may lose the ability to assess their own memory and may be more prone to speculation, therefore, making crossexaminations in court more difficult (Webert, 2003).

Emerging from this debate concerning memory and hypnosis, is the fundamental issue of whether hypnotically refreshed memories meet adequate reliability and validity thresholds for admissibility as evidence in court. Conflicting research findings in this area reflect a profession at odds regarding the extent to which hypnosis taints recall and whether to permit these memories as testimony into the courtroom (Goldstein, 2007). Proponents defend the position that hypnosis has the potential to yield uncontaminated accurate memories under certain circumstances. The American Society for Clinical Hypnosis states that hypnosis can be a valuable tool in forensic work and should be permitted in the courtroom (Karlin, 1997). Advocates of forensic hypnosis point to research indicating that memory inaccuracies are present despite the use of hypnosis, and 
that hypnosis does not necessarily enhance inaccuracies beyond those innate in general memory processes (Neuschatz, Lynn, Benoit, \& Fite, 2003).

On the opposite side of the admissibility debate are those who contend that precise memory recall is rarely achievable under hypnosis and that most memories are confabulated or biased, if not entirely imprecise (Goldstein, 2007). The American Medical Association and the American Psychological Association oppose the admissibility of hypnotically refreshed memories in the courtroom and caution against the use of hypnosis, especially in the recovering of repressed memories of abuse. These differing opinions on admissibility are not only apparent in research, but also in case law decisions.

\section{Judicial Standards}

In the landmark case of Harding v. State (1968), the Court reached a decision allowing the admittance of hypnotically recalled testimony. Since this precedent, hypnosis has been widely used in criminal cases either to discover more facts about a crime, to better a victim's memory prior to testifying, or to aid a victim in dealing with the psychological impact of being a victim to a crime.

Legal decisions regarding hypnotically refreshed testimony vary by jurisdiction. In the case of State v. Mack (1980), the Court held that refreshed or enhanced recollection was regarded as unreliable in the relevant scientific community, and was therefore inadmissible. Under this standard, only the documented prehypnotic memories were admissible as evidence. Other courts have applied a per se admissible rule, holding that hypnotically refreshed testimony is always admissible because the jury is free to assess the credibility of the evidence presented, including the problems and limitations of 
hypnosis. In Beck v. Norris (1986), the Court adopted a different standard: hypnosis affects witness credibility but not the admissibility of their testimony. The credibility of the witness can be judged from the records of the hypnotic sessions, the testimony of any experts, and opportunities to cross-examine the experts and the witness that was hypnotized. The jury is then able to serve its usual capability and weigh the evidence when reaching conclusions.

In courts applying a third standard, testimony is deemed admissible only if certain procedural safeguards have been followed. In State v. Hurd (1981), the court adopted six criteria to ensure that the procedures used to extract memories through hypnosis would result in reliable evidence: (1) the psychotherapist must be trained in the use of hypnosis and actually conduct the session; (2) the psychotherapist should be an impartial party; (3) all information given before the session to the psychotherapist conducting the hypnosis must be recorded in writing; (4) the psychotherapist should obtain from the subject his or her prehypnotic recollections of the incident; (5) all contacts between the subject and the psychotherapist should be recorder (the use of videotape is recommended); and finally (6) only the subject and the psychotherapist should be present during the hypnotic session (Colwick, 1995).

Although these standards represent the positions adopted by a majority of the states, other possible solutions to the question of admissibility of hypnotically refreshed memories have been suggested. In Borawick v. Shay (1995), the Court loosely applied the Hurd safeguard, meaning a case-by-case approach was adopted to determine if the probative value of hypnotically refreshed testimony outweighed any prejudicial effects. The Court held that district attorneys conduct pretrial hearings to consider the issues 
central to hypnosis: purpose, suggestibility, a record of sessions, expert qualifications, corroboration, subject's hypnotizability, and expert testimony regarding reliability. This helps ensure that credible testimony is not precluded from being heard by the jury but still prevents the admissibility of testimony presumed to have been tampered with. (Colwick, 1995).

The only case decided by the United States Supreme Court on the issue of admissibility of hypnotically refreshed testimony is that of Rock v. Arkansas (1987). The Supreme Court held that Arkansas' rule of per se inadmissibility infringes upon criminal defendants' constitutional right to testify on their own behalf. The per se inadmissible rule automatically excludes all testimony that is hypnotically refreshed while some information retrieved may be reliable. Therefore, the Supreme Court implied that a rule that excludes defendants and the other widely accepted approaches (per se admissible, procedural guidelines, case-by-case) would violate one's constitutional rights, leaving individual states to determine the appropriate standard to apply. As a result, a growing number of jurisdictions are moving toward a totality of circumstances analysis, leaving the decision of credibility of hypnotically refreshed memories to the fact finder.

\section{Empirical Evidence}

Empirical evidence concerning the power of hypnosis to enhance accurate recall of recovered memories uncovers mixed findings. A majority of studies conclude that hypnotic procedures do not improve the accuracy of memory much more than nonhypnotic conditions (Erdelyi, 1994; McConkey \& Sheehan, 1996; Kebbell \& Wagstaff, 1998). Erdelyi (1994) found that in some cases, hypnosis resulted in both increases in correct responses as well as incorrect responses to questioning in testimony. Other studies 
find that hypnosis may encourage witnesses to incorporate more misleading information into their testimony, and to generally be more confident in their reports; including reports of incorrect information. Unfortunately, this often results in a false confidence effect (Scoboria, Mazzoni, Kirsch, \& Milling, 2002). Contrary to the results of research findings, popular perceptions of hypnosis are that hypnosis not only improves memory, but also that the more confident the hypnotized witness is in their hypnotically refreshed memories, the more accurate these memories are (Wagstaff, Brunas-Wagstaff, Cole, \& Wheatcroft, 2004). Thus, it is understandable that the average layperson believes hypnotic procedures are expected to enhance accurate memory recall. Public Perceptions

The beliefs and attitudes held by the public about the ability of hypnosis to improve memory occupy an important role both in the behavior of the witness who has been hypnotized, and in the way that this testimony is used in the courtroom (Wilson, Greene, \& Loftus, 1986). Johnson and Hauck (1999) found a large proportion of the general public views hypnosis as a powerful tool to recover accurate memories. Their study of 276 individuals from four population sub-groups revealed that a large number of respondents agreed that hypnosis enables people to recover memories under a variety of conditions including accurate memories as far back as birth or even past lives. Few respondents believed that hypnosis could be faked such that a hypnotist could not tell the difference.

What impact does hypnosis actually have on juror decisions? Wilson and colleagues (1986) found that witness believability ratings awarded by jurors in a hypnotically refreshed memory condition were significantly lower than ratings from 
jurors who heard that the witness' memory was immediate and spontaneous. These results suggest that the participants approached hypnosis with a degree of skepticism, and viewed hypnotically refreshed testimony to have less credibility than immediate report. On the other hand, some studies have found testimony of a witness who had been hypnotized significantly more credibility than one who had not. Labelle, Lamarche, and Laurence (1990) examined a select group of potential jurors' opinions on the effects of hypnosis on eyewitness identification and testimony. Results indicated that a majority of participants believed hypnotic testimony was accurate, and that hypnosis increases the accuracy of the memory of an event. Wagstaff, Vella, and Perfect (1992) examined whether the effects of hypnotically elicited testimony could influence jurors' judgments of guilt and innocence in a simulated criminal trial. They found that participant-jurors were more likely to believe testimony if they were told it had been elicited under hypnosis. Consequently, more jurors were likely to convict a defendant on the basis of testimony elicited through hypnosis than on the basis of testimony elicited with no memory aid. Results of a more recent study examining beliefs of experts and students toward forensic hypnosis found that undergraduates exposed to an educational lecture on hypnosis, endorsed myths of hypnosis less frequently than those not exposed. The expert sample also reflected a more moderate view of the issues in the field of hypnosis. These results suggest that aside from experts in the field, public views of hypnosis have remained consistent, endorsing the technique as an accurate method of memory recall (Knight, 2005). 


\section{Hypnosis in Civil Cases}

Most of the research on hypnotically elicited memories has involved the application of hypnosis in criminal cases, with little attention given to hypnotically recovered memories in civil cases. When hypnosis is used in criminal cases it is typically used to help a witness recall certain specific details of a crime that has been forgotten. In sexual abuse cases, hypnosis is a tool used to recall the entire event (Colwick, 1995).

In sexual abuse cases it must first be decided whether or not the claim will be barred by statue of limitations. Frequently in sexual abuse claims the victim will not remember the trauma until after the statute of limitations has run, which ordinarily means the victim would not have a claim. However, the importance of victims having their day in court must be weighed against the importance of defendants' right of repose in order to determine whether statutes of limitations should toll until memory of the abuse occurs (Spadaro, 1998). Discovery rules accomplish this by delaying the statue of limitations from applying or running until the cause of action has been discovered (Loftus, 1993). Most state courts allow the application of delayed discovery rules in cases involving repressed memories because to do otherwise would leave victims without any recourse for crimes such as sexual abuse (Atkins, 1995).

When a child suffers from sexual abuse, they may choose not to speak out about the abuse. Victims with repressed memories may undergo hypnosis as part of therapy. It is during these hypnotic sessions, possibly years after the abuse, that "memories" of sexual abuse are recalled. Court and state legislatures are continuing to adopt delayed discovery rules that allow civil suits to be brought by survivors of child sexual abuse even after any statute of limitations has expired. Thus, discovery does not take effect until 
they fully understand that the abuse has occurred or made a causal connection between past abuse and present psychological issues (Kanovitz, 1992).

Once a claim of sexual abuse surpasses the applicable statute of limitations, the victim must then deal with admissibility of recovered memory evidence into the courtroom. Very little guidance by state courts exists regarding standards applied specifically to admissibility of repressed memory evidence in civil cases. As previously mentioned, the states apply a variety of standards without any consensus as to which is the best. Therefore the standards of admissibility for forensically-refreshed/recovered memories apply to clinically recovered memories as well according to which jurisdiction and what standard they apply. Some courts prefer applying the approach involving the evaluation of the totality of circumstances.

Applying procedural safeguards becomes difficult with clinically recovered memories since many people recover memories of abuse during therapy irrespective of whether or not any type of legal action will later result. Thus, recordings of the hypnosis sessions may not exist. This becomes problematic, as recordings are one of the suggested procedural safeguards. With that said, if the hypnotically recovered memories are admissible, it will be up to the jurors to evaluate the reliability of the testimony and credibility of the witness (Garrett, 2006). In addition, sexual abuse claims should require a strict standard of proof as they have the potential of producing serious consequences, including severe financial loss and damage to the reputation of accused defendants. Therefore, in civil cases involving claims of sexual abuse discovered by clinical hypnosis, judges must be careful to instruct jurors on the 
appropriate standard of proof in weighing the evidence as well as the hypnotically recovered testimony (Montoya, 1995).

\section{Juror Perceptions}

In the early 1990's, researchers began examining jurors' opinions in delayed discovery trials of child sexual abuse. Most of the research focused on repressed memories of abuse. Loftus in particular, conducted a series of studies investigating opinions about child sexual abuse trials involving memory repression. Results of one study found that potential jurors viewed a daughter's claim of sexual abuse against her father with greater skepticism in the repressed condition as opposed to the non-repressed conditions (1993). Tetford and Schuller (1996) assessed whether participant-jurors’ decisions in a case involving allegations of child sexual abuse would be influenced by the nature of the memory (repressed, nonrepressed) and if therapeutic intervention was present. Results indicated that non-repressed accounts were perceived as more believable than repressed accounts recovered through therapeutic intervention. Bornstein and Muller (2001) examined the credibility of recovered memory testimony in a sexual abuse trial simulation. Results demonstrated that compared to a case where the memory of the abuse had always been remembered, recovered memory testimony led to decreased ratings of the defendant's responsibility and increased ratings of the defendant's credibility. In addition, the victim with recovered memories was viewed as less credible and less likely to be telling the truth. Potential jurors saw recovered repressed memories in a negative light. 


\section{The Effects of Expert Testimony}

The presence of expert testimony in cases of hypnotically recovered memories may present as another factor influencing juror decision-making. Spanos, Gwynn, and Terrade (1989) examined the effects on participant-jurors of experts favorable and unfavorable toward hypnotically elicited testimony. Participants were randomly assigned to one of four conditions: hypnosis with expert in favor of hypnosis v. hypnosis with critical expert v. hypnosis with both experts v. control. Afterward participants were asked to evaluate the defendant's guilt. Results indicated that participant-jurors in the control and favorable expert conditions were more likely to vote guilty than jurors in the unfavorable or conflicting expert conditions. Exposure to an expert critical of hypnotically recovered testimony decreased the frequency with which the defendant received guilty votes, and the opposite was true for jurors exposed to an expert in favor of hypnotically recovered testimony. In another study, Dubreuil (1995) assessed the impact of hypnosis, pretrial preparation, and expert testimony on jurors' assessments of guilt and their perceptions of witness testimony. Half of the participants viewed an expert witness testify about the unreliability of human memory and hypnosis, and the remainder saw no expert. Jurors who viewed the expert voted to acquit the defendant more often than jurors who did not see the expert witness. Results from these studies indicate that experts play an important role in the ways that jurors' perceive hypnotically recovered testimony and may also influence verdict decisions.

Expert testimony also seems to play an imperative role in civil trials. The debate over repressed memories opens the door for experts to testify either in favor or against the credibility of repressed memories and the reliability of these memories once 
recovered (Cupon \& Jahn, 2002). Griffith, Libkuman, and Poole (1998) examined the influence of expert testimony on mock jurors' decision making in a simulated civil repressed memory case. Participants were asked to rate the likelihood that the abuse occurred, the credibility of the accusations, the strengths of each side's case, and award damages. Compared with participant-jurors who were not exposed to expert testimony, jurors exposed to testimony given on behalf of the plaintiff (plaintiff only or both experts conditions) rated the plaintiff's case as stronger and the defendant as more likely to have committed the abuse. Expert testimony of the fallibility of memory did not significantly increase skepticism on the part of the jurors. As a result, jurors were only affected by testimony in favor of the plaintiff. Results of this study appear to contrast with previous research demonstrating that jurors view recovery of repressed memories with skepticism. The presence of expert testimony may serve to moderate jurors' perception of repressed memories and compel them to view repressed memories in a more positive light after exposure to the expert testimony (Griffith et. al, 1998).

A recent study conducted by Nachson et al., (2007) examined the effects of prior knowledge and expert testimony on jurors' beliefs in recovered memories and the credibility they rendered to recovered memory testimony. Participants responded to a questionnaire regarding beliefs and knowledge of recovered memory. In addition, they assessed the credibility of: a victim statement reporting recovery of memories of sexual abuse; a defendant statement denying the allegation and accusing the victim's therapist of implanting false memories of abuse, and two expert witness statements, one each supporting plaintiff and defendant. Results indicated assessments of credibility were related to beliefs about memory recovery and statements made by expert witnesses. 
Irrespective of knowledge and beliefs regarding recovered memories, participants showed a strong tendency to believe the victim's allegations more than the defendant's denial. In addition, expert witness testimony appeared to alter assessments. Participants exposed to an expert for the prosecution in favor of recovered memories were more likely to view the victim's testimony credible, while those exposed to an expert for the defense were more likely to ascribe credibility to the defendant's statements.

\section{Hypnosis in Civil Sexual Abuse Cases}

Few studies have investigated jurors' perceptions of recovered-memories in civil sexual abuse cases when the memories were recovered solely with hypnosis. It seems that with the skepticism surrounding repressed and recovered memories, jurors should perceive hypnotically recovered memories as less credible than non-repressed memories. Coleman, Stevens, and Reeder (2001) investigated participant-jurors' reactions to the recovered-memory testimony of an alleged sexual abuse victim. Participants received instructions to evaluate the accuracy and credibility of the recovered memory testimony before rendering a verdict. These instructions focused jurors on the question of whether hypnosis, as an effective yet unconventional technique, can reveal the truth in this circumstance of repressed memories. When a therapist used hypnosis, jurors viewed the victim's recovered-memory testimony as particularly accurate and credible, and favored the victim in their verdicts. These findings contradict the previously mentioned research claiming that when no expert witness is present or when an expert criticizing repressed memories testifies, jurors view victims with recovered repressed memories of sexual abuse negatively. The fact that a majority of research involving jurors' perceptions of hypnotically-refreshed testimony has shown that jurors perceive hypnosis to be an 
accurate method of memory recall stands in contrast to jurors negative perceptions of repressed memories. It appears that if repressed memories are recovered with hypnosis jurors may find the testimony accurate and credible.

\section{Attitudes}

It appears that attitudes towards and judgments about both offenders and victims relate, in part, to attributions of blame and responsibility (Clements, Brannen, Kirkley, Gordon, \& Church, 2006). Victims, compared to offenders, would seem to be comparatively blameless and deserving of high levels of concern; however, it has been shown that numerous victims elicit high levels of blame attribution (Clements, et al., 2006). The current study presents a case in which the victim was sexually abused 20 years prior to the trial. The victim both remembered the abuse and recently connected it to her present psychological distress, or the victim recovered memories of the abuse with the aid of hypnosis in therapy. Participants' attitudes and concern for the victim become important in this type of sexual abuse trial, and may have the potential to predict the believability/credibility of the victim's testimony.

Currently, as seen throughout the literature, attitudes are a strong predictor of courtroom perceptions, in particular, cases involving hypnosis. For the most part, studies have demonstrated that jurors find hypnotically refreshed testimony as accurate and credible. What has yet to be examined however, is the predictive ability of attitudes and concern for the victim on perceptions of hypnotically recovered memories. The Victim Concern Scale (VCS) measures attitudes towards victims of various types of crimes (Clements, et al., 2006). In the present study we are interested in not only an assessment of attitudes towards victims of sexual abuse as a function of testimony, but also if these 
attitudes are strong enough to predict attitudes towards the victim. To measure these attitudes, the study's researchers developed the Hypnotically refreshed Memory Questionnaire (HRMQ), a 24-item scale designed to measure attitudes toward hypnosis, memory recovered with the aid of hypnosis, repression, and beliefs about memory in general. We anticipate our results will demonstrate the powerful effect of attitudes toward both the victim in a sexual abuse case and hypnotically refreshed memories on judgments of credibility of victim and expert testimony and culpability of the defendant.

\section{Summary}

Studies concerning jurors' perceptions of the recovery of repressed memories have produced differing results, with most studies indicating jurors hold negative opinions of witnesses testifying to repressed memory recovery (Loftus, 1993; Bornstein \& Muller, 2001). In addition, the effect of expert testimony in cases involving recoveredmemories of childhood sexual abuse in civil suits has produced mixed results. Participant-jurors found recovered memory testimony credible in studies only when an expert witness testified in favor of the recovery of repressed memories of childhood sexual abuse. On the other hand, jurors exposed to an expert criticizing repressed memories found witness testimony less credible and favored the defendant (Griffith et. al, 1998; Rotzien, 2002).

Research has also demonstrated that the victim may spontaneously recover repressed memories or recalled through various therapeutic techniques, one such technique being hypnosis (Colwick, 1995). Overall, in criminal trial scenarios, jurors' view hypnosis positively and believe that hypnosis enhances memory recall and find this 
type of testimony as more credible and accurate than testimony not elicited under hypnosis (Labelle et al., 1990; Wagstaff et al., 1992; Knight, 2005).

There is limited research on how jurors in civil cases perceive repressed memories of childhood sexual abuse recovered through the process of hypnosis compared to unassisted memory. Similarly, limited research exists on the effect of expert witness testimony on jurors' perceptions of hypnotically recovered memories of sexual abuse compared to no hypnosis. Thus, jurors' perceptions of these hypnotically recovered memories of childhood sexual abuse and the credibility they place on victim testimony, as well as expert testimony, become an important concern in civil cases for both the plaintiff and the defense. First, depending on the way in which participant-jurors view the hypnotically refreshed testimony, the research may be valuable in assisting plaintiff attorneys in determining whether or not to proceed with similar claims. Secondly, through the use of the questionnaires assessing attitudes toward hypnotically refreshed memories and concern for victims, we will be able to determine whether attitudes will predict the relationship between the type of testimony jurors are exposed to and the believability they ascribe such testimony.

\section{Purpose and Hypotheses}

The present study examined perceptions of hypnosis and hypnotically recovered testimony in a civil suit involving repressed memories of childhood sexual abuse versus victim testimony without the aid of hypnosis. For the purpose of this study, hypnotically recovered testimony refers to testimony given by the victim of childhood sexual abuse elicited in therapy through the process of hypnosis. Hypnosis was be defined using the 
aforementioned clinical definition (American Medical Association, 1958 as cited in Webert, 2003; p. 1301).

Dependent measures of jurors' perceptions were assessed with the HMRQ and VCS. In addition, participants were asked to assess the credibility/believability/accuracy of the plaintiff's testimony, expert testimony, and defendant liability on a 6-point Likerttype scale. One of the major purposes of the present study was to examine whether and to what extent expert witness testimony would shift participant-jurors' perceptions of credibility and liability. Specifically, we were interested in examining the following hypotheses:

- Expert testimony will moderate the relation between plaintiff testimony (hypnotically recovered memories v. memories recovered without hypnosis) and perceptions of defendant liability and the accuracy, believability, and credibility of the plaintiff's testimony.

- Concern for the victim (VCS) and attitudes toward hypnotically refreshed memories (HRMQ) will predict perceptions of defendant liability and the accuracy, believability, and credibility of plaintiff's testimony.

\section{Method}

\section{Participants}

One hundred and eighty-eight undergraduate students participated. Participants were at least 18 years of age and were prescreened for basic jury eligibility. There were 102 females and 88 males ranging from 18 to 44 years of age. Participation required thirty to forty-five minutes depending on stimulus condition. 


\section{Materials}

Pre-Trial Questionnaires. Prior to administering the stimulus materials, participants responded to ten items assessing basic demographic information. In addition, participants completed the 24-item HRMQ and ten items (of 54) from the VCS. These items measure Concern for Victims of Violent Crime and represent the $2^{\text {nd }}$ factor of the four-factor VCS instrument. The items load $\geq .40$ in a Principal Axis with Oblique rotation.

Civil Law Summary. Prior to reading the trial transcripts, participants were read aloud a summary of case-relevant elements of civil law and a description of the burden of proof required in civil cases.

Trial Transcripts. Participants read one of eight trial transcript summaries involving claims of childhood sexual abuse brought against a defendant by an alleged victim. In all eight transcripts, a 30-year-old victim brings claims of sexual abuse against the defendant, which occurred 20 years earlier, when the victim was 10 years old. Transcripts differed on the nature of the abuse memories (repressed memories of sexual abuse uncovered by hypnosis in therapy v. memories of sexual abuse without the use of hypnosis) and the presence of expert witness testimony (no expert witness v. expert on behalf of prosecution v. defense expert v. both). Participants were instructed on the law in all conditions.

Dependent Measures. After reading the transcript, participants completed a single item measuring defendant liability and a series of questions designed to assess the accuracy/ believability/credibility of the victim and expert testimony and how this testimony influenced their verdict. Items were measured using a 6-point Likert-type scale 
ranging from 1 (strongly disagree/not at all credible/ accurate/believable, etc.) to 6 (strongly agree/completely credible/accurate/believable, etc.). Considering that these survey instruments were created solely for the purposes of the current study, reliability and validity have not yet been established. However, items for these instruments were compiled based on different items used in questionnaire assessing similar variables in past research (Nachson et al., 2007, Rotzien, 2002; Coleman et al., 2001; Bornstein \& Muller, 2001; Tetford \& Schuller, 1996; Labelle et al., 1990; Spanos et al., 1989).

\section{Design and Procedure}

The study design was a 2 (Abuse Memories: Recovered through Hypnosis v. Remembered without Hypnosis) x 4 (Expert Testimony: Defense v. Prosecution v. Both v. None) between groups factorial design. Participants were instructed that they would be acting as jurors in a civil sexual abuse trial. Participants then filled out a consent form and were randomly assigned to one of eight conditions. Afterward, participants completed the pre-trial instruments, civil law summary, read the trial transcript summary and instructions, and completed all dependent measures. Participants were thanked for their participation and debriefed. See Appendix for all materials used in this study in the order administered.

\section{Results}

\section{Hypothesis Tests}

Hypothesis 1. A two-way between groups analysis of variance was conducted to test the moderating effects of expert testimony defendant liability, as measured by a 6point Likert scale from $1=$ Not at all liable to $6=$ Completely liable. A significant main

effect of hypnosis was found: $F(1,180)=8.31, p=.004 \eta_{p}{ }^{2}=.044$. Participants in the no 
hypnosis testimony condition found the defendant to be more liable $\left(M_{\text {No Hypnosis }}=4.47\right.$, $S D=1.21)$ compared to those in the hypnosis testimony condition $\left(M_{\text {Hypnosis }}=3.94, S D=\right.$ 1.27). The main effect of expert testimony did not reach statistical significance, nor did the testimony $x$ hypnosis interaction.

Accuracy, Believability, Credibility of Plaintiff Testimony. Correlations of the dependant variables of accuracy, believability and credibility of the plaintiff testimony ranged from .77 to $.84, p<.0001$, with higher levels of credibility associated with higher levels of believability, higher levels of credibility associated with higher levels of accuracy, and higher levels of accuracy associated with higher levels of believability. As a result, a 2 x 4 multivariate analysis of variance was conducted on the accuracy, believability, and credibility of plaintiff testimony. The dependant variables were measured on a 6-point Likert scale from $1=$ Not at all accurate/believable/credible to $6=$ Completely accurate/believable/credible. Overall, there was a significant effect of hypnosis, $F(3,178)=6.19, p=.001 ;$ Wilks' Lambda $=.91 ; \eta_{p}{ }^{2}=.094$. Tests of between subjects' effects revealed significant effects for accuracy, believability, and credibility, at $p<.001$. An inspection of the mean scores indicated that participants in the no hypnosis condition found plaintiff testimony significantly more accurate $(M=4.27, S D=1.12$ vs. $M=3.51, S D=1.28)$, more believable $(M=4.58, S D=1.16$ vs. $M=3.99, S D=1.22)$, and more credible $(M=4.35, S D=1.15$ vs. $M=3.78, S D=1.11)$ compared to participants in the hypnosis condition.

Scale Reliability. After recoding the 24-item Hypnotically Refreshed Memories Questionnaire (HRMQ), Cronbach's alpha $=.80$. In the current study, the 10-item 
Victim Concern (VC) subscale (concern for victims of violent crime) recorded a Cronbach's alpha of .82 .

Scale Development. As can be seen in Table 1, subscales of the HRMQ were created with conceptually related questions having a high degree of face validity. Statistically, there was also a high degree of association among the questions within each subscale. Inter-item correlations for MEMORY ranged from .16 to $.59, p<.05$, JUDGMENT from .14 to .44, $p<.05$, FALSE MEMORY from .27 to $.52, p<.01$, and HYPNOSIS from .16 to .62, $p<.05$. Note that due to our sample size, factor analysis on these data was not deemed appropriate (see Tabachnick \& Fidell, 2007, p. 613). Considering the limited number of items in each subscale, the mean inter-item correlation value is recorded for each subscale and can be seen in Table 1. Hypothesis 2

HRMQ subscales \& VCS: Predicting Defendant Liability. After researchers determined the presence of four subscales of the HRMQ, they were utilized in addressing the hypothesis concerning the predictive ability of the HRMQ along with the VC subscale on participant perceptions of defendant liability.

A multiple regression analysis was conducted to assess the predictive ability of the HRMQ subscales (MEMORY, JUDGMENT, FALSE MEMORY, and HYPNOSIS) and the VCS on defendant liability. The model was significant: $F(5,181)=4.31, p=.001$; $\mathrm{R}^{2}=.11 . M E M O R Y, J U D G M E N T$, and VCS explained $7 \%$ of the $11 \%$ of the Model's variance in defendant liability ratings. Of the five items in the JUDGMENT subscale, Therapists can help individuals make a causal link between childhood sexual abuse and present psychological symptoms and Precise records of all traumatic experiences are 
permanently "stored" in the brain were significantly correlated with liability at $p<.01$. Higher ratings of defendant liability were associated with higher levels of agreement to the two items.

HRMQ subscales \& VCS: Predicting accuracy, believability, and credibility of plaintiff testimony. The researchers in the current study also used the four HRMQ subscales to investigate the hypothesis concerning the predictive ability of the HRMQ along with the VCS on participant perceptions of the accuracy, believability, and credibility of plaintiff testimony (hypnosis vs. no hypnosis).

A multiple regression analysis was conducted to explore the predictive ability of the HRMQ subscales and the VCS on accuracy of plaintiff testimony. The model was significant: $F(5,181)=4.28, p=.001 ; \mathrm{R}^{2}=.11 . M E M O R Y, J U D G M E N T$, and the VCS explained $7 \%$ of the Model's variability with respect to accuracy of plaintiff's testimony. Table 3 displays the unstandardized and standardized coefficients associated with the results of this MRA. A multiple regression analysis was conducted to explore the predictive ability of the HRMQ subscales and the VCS on believability of plaintiff testimony. The model was significant: $F(5,181)=5.425, p<.0001 ; \mathrm{R}^{2}=.13$. MEMORY and JUDGMENT explained $7 \%$ of the total variance in believability of plaintiff testimony. Lastly, a multiple regression analysis was conducted to explore the predictive ability of the HRMQ subscales and the VCS on credibility of plaintiff testimony. The model was significant: $F(5,181)=4.505, p=.001 ; \mathrm{R}^{2}=.11$. MEMORY and JUDGMENT explained $6 \%$ of the total variance in the credibility of plaintiff testimony. Tables $2-5$ display the unstandardized and standardized coefficients associated with the results of each MRA. 


\section{Discussion}

The purpose of the present study was to examine public perceptions of hypnosis and hypnotically recovered testimony in a civil sexual abuse case. Specifically, researchers were interested in the moderating effects of expert testimony on perceptions of defendant liability and the accuracy, believability, and credibility of the plaintiff's testimony. Researchers also hypothesized that concern for the victim and attitudes towards hypnotically recovered memories would predict perceptions of defendant liability and the accuracy, believability, and credibility of the plaintiff's testimony.

Contrary to previous research, the present results indicate that public views of hypnosis and hypnotically recovered memories are more skeptical and disbelieving than past perceptions. In the past, individuals believed that hypnosis not only improved one's memory, but also that it was a powerful tool to recover accurate memories. In addition, previous research reported participants finding the testimony of a hypnotized witness to be more credible and believable than a witness who had not been hypnotized. Past research indicates that participants were more likely to convict a defendant on the basis of testimony elicited through hypnosis compared to testimony elicited without the use of hypnosis.

In the present study, participant-jurors found testimony elicited under hypnosis to be less accurate, less credible, and less believable than testimony not elicited from hypnosis. In addition, participants found the defendant less culpable in conditions involving hypnotically refreshed testimony. It appears that jurors are becoming more sophisticated in their thinking and judging the use of hypnosis more critically than in the past. With the recent false memory debate, and the controversy over hypnosis and 
implantation of false memories, jurors may be more aware of the inaccuracy of hypnotically refreshed memories and the possible suggestibility associated with the use of hypnosis.

The results of the current study did not support the hypothesis examining the moderating effects of expert testimony. Unlike past research, in the current study expert testimony was not shown to moderate measures of defendant liability and the accuracy, believability, and credibility of plaintiff testimony. The only differences that were found among groups were with respect to hypnosis. As previously stated, the defendant was seen as less liable in the hypnotically recovered memories conditions compared to when the memories of sexual abuse were remembered all along. Also, the plaintiff's testimony was seen as less accurate, less credible, and less believable when hypnosis was used to elicit testimony compared to when no hypnosis was utilized. The lack of support for the moderating effect of expert testimony, however, may be due to the fact that expert testimony was only evaluated with respect to the dependant variables of liability of the defendant, and the accuracy, believability, and credibility of the plaintiff's testimony. Future researchers should examine the specific aspects of expert testimony important to participant-jurors' decisions in this context.

One possible explanation for no effect of testimony could be the content of the plaintiff's testimony. Perhaps participants' focus on the victim's testimony minimized any potential effects of expert testimony. However, this can also be viewed as a strength of the current study as the expert testimony conditions should be presented in an evenhanded manner. 
Though not hypothesized, researchers became interested in the possible breakdown of the Hypnotically Refreshed Memories Questionnaire (HRMQ) into individual subscales. The results of the scale development analyses demonstrated four separate subscales of the HRMQ, including Memory, Judgment, False Memory, and Hypnosis. When examined as predictors of defendant liability, and perceptions of the accuracy, believability, and credibility of plaintiff testimony, only the Memory and Judgment subscales reached significance. One reason for this may be that individuals possessed strong opinions on the ability of memory in general, and therefore, were more disbelieving of testimony elicited under hypnosis. Past research has demonstrated hypnosis to increase suggestibility and confabulation; therefore, participants are justified in their disbelief in hypnosis as a method of memory recall.

The Judgment subscale contained items measuring participants' judgment on issues such as distinguishing between true and false memories, making causal links between childhood sexual abuse and adulthood psychiatric symptoms, and the belief that precise records of traumatic incidents are permanently stored in one's brain. Participants holding strong views on judgment items, such as those listed above, demonstrate higher skepticism of the process of hypnosis.

Lastly, it appears that attitudes towards the victim (VCS) and towards hypnotically refreshed memories (HRMQ) demonstrate moderate predictive ability on defendant liability and the accuracy, believability, and credibility of the plaintiff's testimony. The more concerned an individual is for victims of violent crime, the more likely they were to find the defendant liable of the charges in conditions not involving hypnosis. Similarly, the more disbelieving an individual was of hypnosis to recover 
accurate memories, the less accurate, less believable, and less credible they found the plaintiff's testimony under hypnosis and the less liable they found the defendant in hypnosis conditions. Again, it appears that participant-jurors are becoming increasingly skeptical of hypnosis and its use as a method of memory recall.

While the present results should undergo continued examination in the future, it is important to keep in mind the limitations of the present study when generalizing to the directed population. Two limitations of the study were sample selection and sample size. The current sample totaled less than two hundred participants. In the future, a larger sample size may produce more salient and significant results. In addition, the participants in the current study were comprised solely of undergraduate students attending a small university in Rhode Island; therefore, the sample was not very diverse in age or ethnicity. Future research may want to recruit a larger, more diverse sample size in order to generalize results to a greater population of potential jurors.

In addition, the use of written trial transcripts may be viewed as a limitation to the current study. Participants read trial transcripts and were read judges' instructions by the researcher. Future work in this area may want to videotape trial simulations or have individuals participate in a mock trial setting where they are given time to deliberate. It may be interesting to assess whether participants feel differently about expert testimony when viewed live versus when read in a written transcript, or if their opinions of hypnotically refreshed testimony are altered by viewing the plaintiff testify in person as compared to reading the testimony.

Despite these drawbacks, important conclusions can be drawn from this study and utilized by the target population. The present results have strong implications for civil 
sexual abuse cases involving claims of abuse recovered while under hypnosis.

Participant-jurors are becoming more and more skeptical of hypnosis and the accuracy of memories recovered by hypnosis. This information can be valuable in assisting Plaintiff attorneys to determine whether to proceed with similar claims. This information can also prove to help the Defense attorney in building a case for the defendant. In addition, through the continued use of the Hypnotically Refreshed Memories Questionnaire and the Victim Concern Scale to assess attitudes, individuals may be able to predict the relationship between the types of testimony jurors are exposed to and the accuracy, believability, and credibility they will ascribe to such testimony, as well as their perceptions of defendant liability. Continued use of the HRMQ may demonstrate predictive utility of this individual difference factor on the believability of plaintiff testimony regarding the use of hypnosis to recover memories. The present results provide a solid starting point in balancing concerns regarding treatment of spontaneously recovered memories versus claims of abuse recovered while under hypnosis. 


\section{References}

Atkins, L. A. (1995). Remembered memories... True or false? Should the discovery rule be applied to toll the statute of limitations? Capital University Law Review, 24, 581-584.

Beck v. Norris, 801 F.2d 242 (6 ${ }^{\text {th }}$ Cir. 1986).

Borawick v. Shay, 68 F.3d 597, 602-03 (2d Cir. 1995).

Bornstein, B. H. \& Muller, S. L. (2001). The credibility of recovered memory testimony: Exploring the effects of alleged victim and perpetrator gender. Child Abuse \& Neglect, 25, 1415-1426.

Clements, C. B., Brannen, D. N., Kirkley, S. M., Gordon, T. M., \& Church, W. T. (2006). The measurement of concern about victims: Empathy, victim advocacy and the Victim Concern Scale (VCS). Legal and Criminological Psychology, 11, 283295.

Coleman, B. L., Stevens, M. J., \& Reeder, G. D. (2001). What makes recovered-memory testimony compelling to jurors? Law and Human Behavior, 25, 317-338.

Colwick, E. (1995). Hypnotically recalled testimony: Issues facing courts in their determination of its admissibility in civil sexual abuse cases. Law and Psychology Review, 19, 183-201.

Cupon, L. N., \& Jahn, W. T. (2002). The testifying expert: Jurors' perceptions. Journal of the American Chiropractic Association, 39 (9), 46-48.

Dubreuil, S. (1995).Courtroom preparation of hypnotic and nonhypnotic eyewitnesses; Jurors' perceptions of witness testimony and the impact of expert testimony. Dissertation abstracts international, B, The Sciences and Engineering, 55, 5600. 
Erdelyi, M. W. (1994). The empty set of hypermnesia. International Journal of Clinical and Experimental Hypnosis, 42, 379-390.

Garrett, L. R. (2006). Repressed memory evidence in civil sexual abuse cases. Bepress Legal Series. Working Paper 1181.

Goldstein, A. M. (2007). Forensic Psychology: Emerging topics and expanding roles. New Jersey: John Wiley \& Sons, Inc.

Griffith, J. D., Libkuman, T. M., \& Poole, D. A. (1998). Repressed memories: The effects of expert testimony on mock jurors' decision making. American Journal of Forensic Psychology, 16, 5-23.

Harding v. State, 246 A.2d 302, 306 (Md. Ct. Spec. App. 1968).

Johnson, M. E., \& Hauck C. (1999). Beliefs and opinions about hypnosis held by the general public: A systematic evaluation. The American Journal of Clinical Hypnosis, 42, 10-20.

Kanovitz, J. (1992). Hypnotic memories and civil sexual abuse trials. Vanderbilt Law Review, 45, 1185-1262.

Karlin, R. A. (1997). Illusory safeguards: Legitimizing distorted recall with guidelines for forensic hypnosis: Two case reports. International Journal of Clinical and Experimental Hypnosis, 45, 18-40.

Kebbell, M. R., \& Wagstaff, G. F. (1998). Hypnotic Interviewing: The best way to interview eyewitnesses? Behavioral Sciences and the Law, 16, 115-129.

Knight, S. C. (2005). Beliefs toward forensic hypnosis: An expert sample versus an undergraduate sample with an educational lecture manipulation. Dissertation Abstracts International: Section B: the Sciences and Engineering, 65, 4292. 
Labelle, L., Lamarche, M. C., \& Laurence, J. (1990). Potential jurors' opinions on the effects of hypnosis on eyewitness identification: A brief communication. International Journal of Clinical and Experimental Hypnosis, 38, 315-319.

Loftus, E. (1993) The reality of repressed memories. American Psychologist, 48, 518537.

McConkey, K. M., \& Sheehan, P. W. (1996). Hypnosis, Memory, and Behavior in Criminal Investigation. New York: Guilford.

Montoya, J. M. (1995). Requiring clear and convincing proof in tort claims involving recently recovered repressed memories. Southwestern University Law Review, 25, 173-198.

Nachson, I. et al. (2007). Effects of prior knowledge and expert statement on belief in recovered memories: An international perspective. International Journal of Law and Psychiatry, 30, 224-236.

Neuschatz, J. S., Lynn, S. J., Benoit, G. E., \& Fite, R. (2003). Hypnosis and memory illusions: An investigation using the Deese/Roediger and McDermott paradigm. Imagination, Cognition, and Personality, 22, 3-12.

Rock v. Arkansas, 483 U.S. 22 (1987).

Rotzien, A. L. (2002). Factors influencing juror verdicts in a case involving repressed memories of abuse. Current Psychology; Developmental, Learning, Personality, and Social, 21, 220-239.

Scoboria, A., Mazzoni, G., Kirsch, I., \& Milling, L. S. (2002). Immediate and persisting effects of misleading questions and hypnosis on memory reports. Journal of Experimental Psychology: Applied, 8, 26-32. 
Spadaro, J. A. (1998). Note: An elusive search for the truth: The admissibility of repressed and recovered memories in light of Daubert v. Merrell Dow Pharmaceuticals, Inc. Connecticut Law Review, 30, 1147-1198.

Spanos, N. P., Gwynn, M. I., and Terrade, K. (1989). Effects on mock jurors of experts favorable and unfavorable toward hypnotically elicited eyewitness testimony. Journal of Applied Psychology, 74, 922-926.

State v. Hurd, 432 A.2d 86 (N.J. 1981).

State v. Mack, 292 N.W.2d 764, 772 (Minn. 1980).

Tabachnick. B. G., \& Fidell, L. S. (2007). Using multivariate statistics $\left(5^{\text {th }}\right.$ ed.). Boston: Pearson.

Tetford, I., \& Schuller, R. A. (1996). Mock jurors' evaluations of child sexual abuse: The impact of memory recovery and therapeutic intervention. Behavioral Sciences and the Law, 14, 205-218.

Wagstaff, G. F., Brunas-Wagstaff, J., Cole, J., \& Wheatcroft, J. (2004). New directions in forensic hypnosis: Facilitating memory with a focused meditation technique. Contemporary Hypnosis, 21, 14-28.

Wagstaff, G. F., Vella, M., \& Perfect, T. (1992). The effect of hypnotically elicited testimony on juror's judgments of guilt and innocence. Journal of Social Psychology, 132, 591-595.

Webert, D.R. (2003). Are the courts in a trance? Approaches to the admissibility of hypnotically enhanced testimony on light of empirical evidence. The American Criminal Law Review, 40, 1301-1327. 
Wilson, L., Greene, E., \& Loftus, E.G. (1986). Beliefs about forensic hypnosis. International Journal of Clinical and Experimental Hypnosis, 34, 110-121. 
Table 1. Mean Responses to Survey Questions Clustered within Subscales

Items

Rating (1-6)

MEMORY Subscale $\left(M_{\text {Inter-Item }} r=.22\right)$

Mean

SD

1. It is possible for an individual to remember things that they have forgotten for years.

4.73

2. Recovered memories of past events are accurate.

3.36

3. It is possible to accurately remember events that happened

4.49 in childhood 20 years later.

4. Therapists can help people remember things. 4.14

5. Memories of painful events can be forgotten or repressed. $\quad 3.85$

6. Memories from childhood can be repressed.

4.45

JUDGMENT Subscale $\left(M_{\text {Inter-Item }} r=.29\right)$

7. People can distinguish between true and false memories.

8. Therapists can help individuals make a causal link between childhood sexual abuse and present $\quad 4.54$ psychological symptoms.

9. Individuals can be sexually abused as a child and never $\quad 5.38$ talk about it with anyone.

10. Specific psychiatric symptoms in adulthood are strongly $\quad 4.14$ indicative of childhood sexual abuse.

11. Precise records of all traumatic experiences are permanently "stored" in the brain.

FALSE MEMORY Subscale ( $M_{\text {Inter-Item }} r=.27$ )

12. Using hypnosis to recover memories often causes people to confabulate, or fill in gaps of their memory with false information.

13. Hypnosis can cause false memories.

14. Using hypnosis to recover memories often causes people to recall things that did not happen.

15. Memories recovered by hypnosis are often unreliable and $\quad 3.54$ inaccurate representations of the truth.

16. Therapists can plant false memories of sexual abuse into $\quad 3.39$ an individual's conscious mind.

HYPNOSIS Subscale $\left(M_{\text {Inter-Item }} r=.36\right)$

3.28

17. Hypnosis is an accurate method of memory recall.

18. Memories recovered with hypnosis are always accurate.

19. Testimony by a witness of memories recovered by hypnosis usually represents the true state of affairs.

20. Hypnotized individuals remember details accurately $\quad 3.74$ w/hypnosis.

2.48

21. Repressed memories can be recovered with hypnosis.

22 . The content of $h-r$ testimony is always accurate.

23. Testimony of a witness who has been hypnotized is more 3.62 credible than testimony of a witness who has not been 
hypnotized.

24. Hypnosis increases a witness' confidence in the accuracy of his/her memories and testimony. 
Table 2. Summary of MRA for Variables Predicting Defendant Liability

\begin{tabular}{llcc}
\hline Variable & $B$ & SE B & $\beta$ \\
\hline VC Subscale & .050 & .023 & .158 \\
HYPNOSIS Subscale & -.007 & .016 & -.036 \\
FALSE MEMORY Subscale & .027 & .026 & .076 \\
MEMORY Subscale & .047 & .023 & .161 \\
JUDGMENT Subscale & .067 & .030 & .169 \\
\end{tabular}

Note. $R^{2}=.11, \Delta R^{2}=.08(p s<.05)$. Dependent variable: How liable do you feel the defendant is for sexually abusing the victim. $N=186$ for all MRA Tables. 
Table 3. Summary of MRA for Variables Predicting Accuracy of Plaintiff's Testimony

\begin{tabular}{llcc}
\hline Variable & $B$ & SE B & $\beta$ \\
\hline VC Subscale & .044 & .023 & .142 \\
HYPNOSIS Subscale & -.001 & .016 & -.006 \\
FALSE MEMORY Subscale & -.016 & .025 & -.046 \\
MEMORY Subscale & .053 & .023 & .184 \\
JUDGMENT Subscale & .059 & .030 & .149 \\
\end{tabular}

Note. $R^{2}=.11, \Delta R^{2}=.09(p s<.05)$. Dependent variable: How accurate do you find the victim's memories of childhood sexual abuse. 
Table 4. Summary of MRA for Variable Predicting Believability of Plaintiff's Testimony

\begin{tabular}{lllc}
\hline Variable & $B$ & SE B & $\beta$ \\
\hline VC Subscale & .033 & .022 & .107 \\
HYPNOSIS Subscale & .000 & .015 & -.001 \\
FALSE MEMORY Subscale & .004 & .024 & .010 \\
MEMORY Subscale & .061 & .022 & .215 \\
JUDGMENT Subscale & .075 & .029 & .194 \\
\end{tabular}

Note. $R^{2}=.13, \Delta R^{2}=.11(p s<.01)$. Dependent variable: How believable did you find the victim's testimony alleging the defendant sexually abused her in this case. 
Table 5. Summary of MRA for Variable Predicting Credibility of Plaintiff's Testimony

\begin{tabular}{lllc}
\hline Variable & $B$ & SE B & $\beta$ \\
\hline VC Subscale & .037 & .021 & .128 \\
HYPNOSIS Subscale & -.012 & .015 & -.063 \\
FALSE MEMORY Subscale & .007 & .024 & .021 \\
MEMORY Subscale & .052 & .021 & .192 \\
JUDGMENT Subscale & .070 & .028 & .191 \\
\end{tabular}

Note. $R^{2}=.11, \Delta R^{2}=.08(p s<.05)$. Dependent variable: How credible did you find the victim's testimony alleging the defendant sexually abused her in this case. 


\section{Appendix A}

\section{Informed Consent Form}

Title of Project: Understanding Juror Perceptions of Hypnotically Recovered Memories in a Civil Sexual Abuse Case

Principal Investigator: Samantha Fusco

1. Purpose of the Study: The present research will attempt to examine juror perceptions of hypnosis and hypnotically-recovered testimony in a civil sexual abuse case. This study also aims to investigate the effects of expert witness testimony on jurors' perceptions of victim credibility and on juror decision making. It is predicted that expert testimony will moderate the relation between victim testimony and perceptions of hypnotically recovered memory. In addition, we expect that the effects of our manipulations will be mediated by attitudes towards hypnotically refreshed memories and perceptions of the victim.

2. Procedures Experienced by Participants: You will be instructed as if you are acting as a juror in a civil sexual abuse case. You will be randomly assigned to one of eight conditions and will complete pre-trial instruments, a civil law summary, read a trial transcript summary and instructions, and complete all dependent measures on the given questionnaire which varies slightly based on the condition you have been exposed to. You will then be given a debriefing statement as you leave. This study should take no more than thirty to forty-five minutes to complete.

3. Statement of Confidentiality: Your participation in this research is confidential. Only the investigator above has access to your responses, which will ensure your confidentiality. In addition, your name will only appear on the written consent form, which will be collected and kept separate from your questionnaire. Thus your responses will also remain anonymous. In the event of publication, pseudonyms will be used.

4. Your Rights: You have the right to decline participation in this study without any penalties because participation is strictly voluntary. At any point in the study, you have the right to withdraw without penalty or prejudice. You may also ask questions at any time during the study and you may contact the principal investigator at any time after participation (name, email address, and phone number appear at bottom of this form).

5. Compensation: Participation is part of a course requirement or for extra credit. No monetary compensation will be provided.

More Information: After participation, please feel free to contact Samantha L. Fusco by telephone (774) 239 4141 or via email sfusco036@hawks.rwu.edu should you have additional questions.

This is to certify that I have given my full consent to participate in this research study. I am at least 18 years of age or older. I have read this form and fully understand the content.

Participant's signature

Date

This is to certify that I have defined and explained this research study to the participant named above.

Principal Investigator

Date 


\section{Pre-Trial Questionnaire}

Please answer the following items by placing a check in the box that best describes you.

Your gender:
$\square \quad$ Male
Female

Into which of the following age categories do you fall:

$18-24$

25-34

$35-44$

$45-54$

$55-64$

65 and older

Which of the following characterizes your background?

Caucasian

Hispanic

African-American

Other

Your marital status:

Single

Married

Separated

Divorced

Widowed 
Do you have any children?

No

Yes

What is the highest level of education you have completed?

Elementary School

High School

Partial College or junior college

College degree

Post-graduate college degree

What is your employment status?

Not working now/unemployed

Retired

Student

Homemaker

Employed full-time

Employed half-time

Which of the following characterizes any previous jury service?

Juror in criminal trial

Juror in civil trial

Juror in both civil and criminal trial

Never served as a juror 


\section{Hypnosis and Repressed Memories Questionnaire (HRMQ)}

For each of the following statements, please circle the number that best reflects your opinion.

Memories from childhood can be repressed.
1
2
3
4
5
6

Strongly Disagree

Strongly Agree

Memories of painful events can be forgotten or repressed.
1
2
3
4
5
6

Strongly Disagree

Strongly Agree

It is possible for an individual to remember things that they have forgotten for years.

1

2

Strongly Disagree

Recovered memories of past events are accurate.
2

Strongly Disagree

Therapists can help people remember things.
2

3

4

5

6

Strongly Agree

Strongly Disagree

4

5

6

Strongly Agree

Repressed memories can be recovered with hypnosis.

1

2

3

4

5

6

Strongly Disagree 
Hypnosis is an accurate method of memory recall.
1
2
3
4
5
6

Strongly Disagree

Strongly Agree

Memories recovered with the help of hypnosis are always accurate.
1
2
3
4
5
6

Strongly Disagree

Strongly Agree

Using hypnosis to recover memories often causes people to recall things that did not happen.
1
2
3
4
5
6

Strongly Disagree

Strongly Agree

Using hypnosis to recover memories often cause people to confabulate, or fill in gaps of their memory with false information.
1
2
3
4
5
6

Strongly Disagree

Strongly Agree

Hypnotized individuals remember details more accurately with the use of hypnosis.
1
2
3
4
5
6

Strongly Disagree

Strongly Agree

Memories recovered by hypnosis are often unreliable and inaccurate representations of the truth.
1
2
3
4
5
6

Strongly Disagree

Strongly Agree 
Testimony by a witness of memories recovered by hypnosis usually represents the true state of affairs.
1
2
3
4
5
6

Strongly Disagree

Strongly Agree

Hypnosis increases a witness's confidence in the accuracy of his/her memories and testimony.
1
2
3
4
5
6

Strongly Disagree

Strongly Agree

Hypnosis can cause false memories.
1 2
3
4
5
6

Strongly Disagree

Strongly Agree

The content of hypnotically recovered testimony is always accurate.
1
2
3
4
5
6

Strongly Disagree

Strongly Agree

Testimony of a witness who has been hypnotized is more credible than testimony of a witness who has not been hypnotized.
1
2
3
4
5
6

Strongly Disagree

Strongly Agree

Generally, people can distinguish between true and false memories.
1
2
3
4
5
6

Strongly Disagree

Strongly Agree 
Specific psychiatric symptoms in adulthood are strongly indicative of childhood sexual abuse.
1
2
3
4
5
6

Strongly Disagree

Strongly Agree

Therapists can help individuals make a causal link between childhood sexual abuse and present psychological symptoms.
1
2
3
4
5
6

Strongly Disagree

Strongly Agree

Precise records of all traumatic experiences are permanently "stored" in the brain.
1 2
3
4
5
6

Strongly Disagree

Strongly Agree

Therapists can plant false memories of sexual abuse into an individual's conscious mind.
1
2
3
4
5
6

Strongly Disagree

Strongly Agree

Individuals can be sexually abused as a child and never talk about it with anyone.

1 2

3

4

5

6

Strongly Disagree

Strongly Agree

It is possible to accurately remember events that happened in childhood 20 years later. 1 2 3

4

5

6

Strongly Disagree

Strongly Agree 
Victim Concern Scale (VCS)

Using the scale listed below, indicate by circling the number that best reflects your opinion, to what extent you think people should be concerned about the following victims.

Victims of kidnapping

1

Not at all Concerned

Victims of sexual harassment
1
2

3

Not at all Concerned

Victims of violent assault

1

Not at all Concerned

2

3

Child victims

$$
1
$$$$
2
$$

3

Not at all Concerned

Victims of domestic assault

1

Not at all Concerned

Families of murder victims

1

2

3

Not at all Concerned
4 5

Extremely Concerned

4

5

Extremely Concerned

Extremely Concerned

4

5

Extremely Concerned

45

Extremely Concerned

Extremely Concerned 
Female victims
1
2
3
4
5

Not at all Concerned

Extremely Concerned

Victims of child molestation

1

3

4

5

Not at all Concerned

Extremely Concerned

Victims of rape$$
1
$$

2

3

4

5

Not at all Concerned

Victims of hate crimes

$\begin{array}{lll}1 & 2 & 3\end{array}$

4 5

Not at all Concerned

Extremely Concerned 


\section{Civil Law Summary}

Civil law is the area of law governing relations between private individuals. In civil litigation a defendant is never incarcerated and never executed. In general, a losing defendant in civil litigation reimburses the plaintiff for losses caused by the defendant's behavior. In a civil case under tort law, there is a possibility of punitive damages, if the defendant's conduct is egregious and had either (1) a malicious intent (i.e., desire to cause harm), (2) gross negligence (i.e., conscious indifference), or (3) a willful disregard for the rights of others. The use of punitive damages makes a public example of the defendant and supposedly deters future wrongful conduct by others. Punitive damages are particularly important in torts involving dignitary harms (e.g., invasion of privacy) and civil rights. The level of burden of proof in this case is "clear and convincing evidence." To prove something by "clear and convincing evidence", the party with the burden of proof must convince you as a juror in this case, that it is substantially more likely than not that the allegations are true. This is a lesser requirement than "proof beyond a reasonable doubt", which requires that you as a juror be close to certain of the truth of the matter asserted, but a stricter requirement than proof by "preponderance of the evidence," which merely requires that the matter asserted seem more likely true than not. In civil law cases, the "burden of proof" requires the plaintiff to convince the jury of the plaintiff's entitlement to the relief sought. This means that the plaintiff must prove each element of the claim, or cause of action, in order to recover. In a civil suit, the credibility of witnesses and the weight to be given to their testimony are matters for you, as a juror, to determine. You will be asked to weigh the testimony and evidence of the trials and render a verdict either in favor of the plaintiff or in favor of the defendant. 


\section{Trial Transcripts}

\section{Condition 1: Hypnosis, No Experts}

\section{Direct Examination of the Victim}

JUDGE: Today we are hearing evidence in the case of Jennifer Riley v. Robert Smith.

The defendant, Mr. Smith is accused of sexually abusing the Plaintiff, Ms. Riley, 20

years prior to this trial. Mr. Morin (Plaintiff's attorney) would you like to call your first witness?

A: Yes, your honor. I would like to call Jennifer Riley to the stand.

OATH: Do you solemnly swear you will tell the truth and nothing but the truth, so help you?

\section{A: Yes.}

Q: Please state your full name?

A: My name is Jennifer Riley.

Q: What brings you to court today Jennifer?

A: I am filing suit for damages endured as a result of repeated sexual abuse.

Q: When did this abuse occur Jennifer?

A: Twenty years ago when I was 10 years old.

Q: Who is the person that abused you when you were such a young child?

A: That man (points to the defendant), my uncle Robert.

Q: And why did it take 20 years for you to file charges against Robert?

A: I was not aware of the childhood abuse until I recovered the memories recently in therapy through the process of hypnosis with Dr. Dunbar. My memories were deeply repressed and I had no awareness of the abuse. 
Q: Why did you seek therapy Jennifer?

A: For as long as I can remember, I have experienced intense psychological symptoms of depression and anxiety. The depression and distress has been so severe that it has affected my work, intimate and personal relationships, and everyday life. Some days are so bad I cannot even get out of bed. My distrust of others has prevented any sort of long-term relationships and there are times when I feel completely hopeless and helpless. Q: You said you recovered the abuse through hypnosis in therapy. Tell me about that. A: Among other relaxation techniques, Dr. Dunbar offered hypnosis and regression therapy, which assists in returning to a childhood state to help heal symptoms and relieve distress. Through hypnosis, I uncovered vivid and repetitive memories of sexual abuse perpetrated by Uncle Robert in the summer of 1988, when I was 10 years old.

Q: As painful as it is, can you please describe the memories you uncovered for the jury. A: That summer I stayed at my aunt and uncles during the weeks while my parents were at work. During this time, Uncle Robert would take me into the cabana by the swimming pool in the backyard and force me to remove my clothes. He would order me to perform oral sex on him and then would force me to have intercourse with him. He covered my mouth to prevent my screams of pain and after it was done, he made me get dressed and said if I ever told anyone, bad things would happen to my parents and I.

Q. At any point during therapy, did Dr. Dunbar suggest your symptoms may have been the result of childhood sexual abuse?

A: No. Dr. Dunbar never once made any suggestions or accusations.

Q. When did the issue of sexual abuse arise in therapy? 
A. It was not until I recovered the memories with the aid of hypnosis and discussed them afterwards with Dr. Dunbar, that we began to talk about the possible implications. Q: Did Dr. Dunbar ask you about any abuse after the hypnosis sessions?

A: No. I recalled the memories and was mortified. I brought them to Dr. Dunbar's attention and we began to work through my psychological problems that I now knew were the result of the childhood abuse.

Q: How long would you say you have suffered the ramifications of the abuse committed against you by the defendant?

A: My whole life has been plagued by depression and distress. Even presently, I still suffer from residual symptoms of the abusive memories. The medical bills and therapy sessions are numerous and he (the defendant) is to blame.

Mr. Morin: No further questions your honor.

\section{Cross-Examination of the Victim}

JUDGE: Mr. Dennehy (defense attorney), would you like to question the witness? Mr. Dennehy: Yes, thank you your honor.

Q: Good afternoon, Jennifer, I am Mr. Dennehy, the defense attorney in this case. I would like to ask you a few questions regarding your memories of abuse. When did you say you began attending therapy with Dr. Dunbar?

A: About one year ago.

Q: And how long into therapy were you before hypnosis was utilized to help relieve any symptoms?

A: About 3 or 4 months in.

Q: Why was hypnosis used in your therapy sessions after that point? 
A: My symptoms were severe and persistent, so Dr. Dunbar offered hypnosis as an alternative technique to try and help with symptom relief.

Q: So Dr. Dunbar suggested you use hypnosis to uncover memories?

A: No. She offered hypnosis as an option and I accepted.

Q: And with hypnosis you uncovered these vivid memories of abuse?

A: Yes. After hypnosis was used, I was able to describe in detail these memories of abuse.

Q: Did you have any recollections of abuse before the hypnosis was used?

A: No, the memories were repressed.

Q: Did you remember spending summers at your aunt and uncles?

A: Yes I did.

Q: SO you remember being at your aunt and uncles in the summer as a child, but you do not remember any instances of abuse prior to hypnosis in therapy?

A: Yes, that's correct.

Q: Did you ever consider that these alleged vivid memories, were nothing more than imagined instances, implanted during hypnosis in therapy?

A: No, they are real memories.

Q: But if you can remember being there in the summer, don't you think you would remember such abuse?

A: My memories were deeply repressed. They are traumatic real memories that I repressed and recovered in therapy with the help of hypnosis. This does not make my memories any less real.

Q: You have been experiencing psychological symptoms for a while Jennifer? 
A: Yes, for as long as I can remember.

Q: And I certain that you would give anything to figure out the origin or cause of those symptoms, for relief?

A: Well, yes of course.

Q: Is it possible, that you wanted answers so badly that your mind created the memories of abuse as a way to cope with your symptoms, and recalled them after hypnosis as vivid memories?

A: No. That is not what happened. Hypnosis helped me remember what already happened. Uncle Robert took my innocence. He abused me when I was just 10 years old and the truth will finally come out.

Mr. Dennehy: No further questions your honor.

\section{Condition 2: Hypnosis/Expert Plaintiff}

Direct Examination of the Victim

JUDGE: Today we are hearing evidence in the case of Jennifer Riley v. Robert Smith. The defendant, Mr. Smith is accused of sexually abusing the Plaintiff, Ms. Riley, 20 years prior to this trial. Mr. Morin (prosecuting attorney) would you like to call your first witness?

A: Yes, your honor. I would like to call Jennifer Riley to the stand.

OATH: Do you solemnly swear you will tell the truth and nothing but the truth, so help you?

A: Yes.

Q: Please state your full name? 
A: My name is Jennifer Riley.

Q: What brings you to court today Jennifer?

A: I am filing suit for damages endured as a result of repeated sexual abuse.

Q: When did this abuse occur Jennifer?

A: Twenty years ago when I was 10 years old.

Q: Who is the person that abused you when you were such a young child?

A: That man (points to the defendant), my uncle Robert.

Q: And why did it take 20 years for you to file charges against Robert?

A: I was not aware of the childhood abuse until I recovered the memories recently in therapy through the process of hypnosis with Dr. Dunbar. My memories were deeply repressed and I had no awareness of the abuse.

Q: Why did you seek therapy Jennifer?

A: For as long as I can remember, I have experienced intense psychological symptoms of depression and anxiety. The depression and distress has been so severe that it has affected my work, intimate and personal relationships, and everyday life. Some days are so bad I cannot even get out of bed. My distrust of others has prevented any sort of long-term relationships and there are times when I feel completely hopeless and helpless.

Q: You said you recovered the abuse through hypnosis in therapy. Tell me about that. A: Among other relaxation techniques, Dr. Dunbar offered hypnosis and regression therapy, which assists in returning to a childhood state to help heal symptoms and relieve distress. Through hypnosis, I uncovered vivid and repetitive memories of sexual abuse perpetrated by Uncle Robert in the summer of 1988, when I was 10 years old. Q: As painful as it is, can you please describe the memories you uncovered for the jury. 
A: That summer I stayed at my aunt and uncles during the weeks while my parents were at work. During this time, Uncle Robert would take me into the cabana by the swimming pool in the backyard and force me to remove my clothes. He would order me to perform oral sex on him and then would force me to have intercourse with him. He covered my mouth to prevent my screams of pain and after it was done, he made me get dressed and said if I ever told anyone, bad things would happen to my parents and I.

Q. At any point during therapy, did Dr. Dunbar suggest your symptoms may have been the result of childhood sexual abuse?

A: No. Dr. Dunbar never once made any suggestions or accusations.

Q. When did the issue of sexual abuse arise in therapy?

A. It was not until I recovered the memories with the aid of hypnosis and discussed them afterwards with Dr. Dunbar, that we began to talk about the possible implications. Q: Did Dr. Dunbar ask you about any abuse after the hypnosis sessions?

A: No. I recalled the memories and was mortified. I brought them to Dr. Dunbar's attention and we began to work through my psychological problems that I now knew were the result of the childhood abuse.

Q: How long would you say you have suffered the ramifications of the abuse committed against you by the defendant?

A: My whole life has been plagued by depression and distress. Even presently, I still suffer from residual symptoms of the abusive memories. The medical bills and therapy sessions are numerous and he (the defendant) is to blame. Mr. Morin: No further questions your honor. 


\section{$\underline{\text { Cross-Examination of the Victim }}$}

JUDGE: Mr. Dennehy (defense attorney), would you like to question the witness?

Mr. Dennehy: Yes, thank you your honor.

Q: Good afternoon, Jennifer, I am Mr. Dennehy, the defense attorney in this case. I would like to ask you a few questions regarding your memories of abuse. When did you say you began attending therapy with Dr. Dunbar?

A: About one year ago.

Q: And how long into therapy were you before hypnosis was utilized to help relieve any symptoms?

A: About 3 or 4 months in.

Q: Why was hypnosis used in your therapy sessions after that point?

A: My symptoms were severe and persistent, so Dr. Dunbar offered hypnosis as an alternative technique to try and help with symptom relief.

Q: So Dr. Dunbar suggested you use hypnosis to uncover memories?

A: No. She offered hypnosis as an option and I accepted.

Q: And with hypnosis you uncovered these vivid memories of abuse?

A: Yes. After hypnosis was used, I was able to describe in detail these memories of abuse.

Q: Did you have any recollections of abuse before the hypnosis was used?

A: No, the memories were repressed.

Q: Did you remember spending summers at your aunt and uncles?

A: Yes I did. 
Q: SO you remember being at your aunt and uncles in the summer as a child, but you do not remember any instances of abuse prior to hypnosis in therapy?

A: Yes, that's correct.

Q: Did you ever consider that these alleged vivid memories, were nothing more than imagined instances, implanted during hypnosis in therapy?

A: No, they are real memories.

Q: But if you can remember being there in the summer, don't you think you would remember such abuse?

A: My memories were deeply repressed. They are traumatic real memories that I repressed and recovered in therapy with the help of hypnosis. This does not make my memories any less real.

Q: You have been experiencing psychological symptoms for a while Jennifer?

A: Yes, for as long as I can remember.

Q: And I certain that you would give anything to figure out the origin or cause of those symptoms, for relief?

A: Well, yes of course.

Q: Is it possible, that you wanted answers so badly that your mind created the memories of abuse as a way to cope with your symptoms, and recalled them after hypnosis as vivid memories?

A: No. That is not what happened. Hypnosis helped me remember what already happened. Uncle Robert took my innocence. He abused me when I was just 10 years old and the truth will finally come out.

Mr. Dennehy: No further questions your honor. 


\section{Direct Examination of Plaintiff Expert}

Q: Please state your name for the court.

A: My name is Dr. Rachel Dunbar.

Q: Dr. Dunbar, would you please describe your credentials for the court?

A: I earned my undergraduate degree at State University and then earned a Ph. D. in clinical psychology. I am a clinician and researcher specializing in repressed memory, hypnosis, and counseling. I am also a certified clinical hypnotherapist by the American Institute of Hypnotherapy and have nearly 25 years of practical experience. I practiced under Martin Orne in England for many years and have taught courses at the undergraduate and graduate level. I am a member of the American Association of Professional Hypnotherapists, author of 15 books and over 50 articles for prestigious psychological journals, and both attend and conduct lectures on the clinical uses of hypnosis.

Q: Was Jennifer Riley one of your clients in therapy?

A: Jennifer came to my office seeking therapy for a number of reasons. She was suffering from long-term depression and anxiety. She was having trouble sleeping, eating, at work, at home, and in her relationships.

Q: When did you offer hypnosis as an option?

A: About 3 or 4 months into therapy, I offered hypnosis as an option to help relieve some of Jennifer's symptoms. With hypnosis age regression and/or relaxation, the client has access to unconscious memories and motives, which may be the cause of present psychological symptoms. Jennifer was a fitting candidate for hypnosis. Q: Did you ever force Jennifer to partake in hypnosis? 
A: Never. The process was voluntary and Jennifer was eager to try the procedure. Q: How does hypnosis work Dr. Dunbar?

A: Well, during hypnosis the client is coached into a state of deep relaxation, using eyefixation or counting techniques. Once in this relaxed state, clients are able to relive prior experiences, uncover repressed memories, and have access to the unconscious mind. Once awakened from hypnosis, the client may begin to recall events they had no recollection of prior to hypnosis. These repressed memories could have some influence on their present psychological distress.

Q: Describe for the court what you mean by repressed memories.

A: The human mind is akin to a videotape recorder that stores away almost all experiences. Traumatic experiences, such as sexual abuse, can often be repressed or forced into the unconscious mind. An individual may have no recollection of such traumatic memories. Repressed memories can be spontaneously recovered or can be recovered through different processes, one being hypnosis. Once the memory is brought into the conscious mind, it is no longer forgotten or repressed.

Q: Are you aware of the Guidelines set forth regarding hypnosis in therapy and admissibility in court?

A: Yes, I am extremely aware of such guidelines and always follow them in my practice. Clients are very suggestible under hypnosis and I would not want to do anything that would interfere with their experience or implant memories that did not occur. Q: Did you, at any point in time, suggest to Jennifer that she had been sexually abused as a child?

A: No, I did not make any such suggestions. 
Q: When was the subject of abuse brought about in therapy?

A: After some hypnosis sessions, Jennifer came to therapy and disclosed the memories of abuse to me. We began discussing these memories and Jennifer began to link the memories to her current distress.

Q: Did you ever once try to implant false memories of abuse or alter Jennifer's memories in any way with the use of hypnosis?

A: Absolutely not.

Q: Dr. Dunbar, do you believe that Jennifer's repressed memories of abuse represent the true state of affairs and can be considered credible?

A: It is my opinion that Jennifer's memories are both accurate and credible. I believe they are vivid representations of the true state of affairs 20 years ago.

Mr. Morin: Thank you. No further questions your honor.

\section{Cross-Examination of Plaintiff Expert}

JUDGE: Mr. Dennehy, would you like to question the witness?

Mr. Dennehy: Yes, thank you, your honor.

Q: Dr. Dunbar, you discussed the process of hypnosis in therapy earlier, remarking that the client may become highly suggestible?

A: Yes, that is correct. In such a state of deep relaxation, clients are more vulnerable to suggestions.

Q: Would you say that the Plaintiff, Jennifer, was in such a state of deep relaxation during your hypnosis session?

A: Well, yes, I would say Jennifer reached that relaxation state.

Q: So, Jennifer was in a state of relaxation where she was also highly suggestible? 
A: That is correct.

Q: How long have you practiced hypnosis doctor?

A: For over 25 years.

Q: And in those 25 years have you ever made suggestions to a client during hypnotherapy?

A: Well, there are different types of suggestions...

Q: Yes or no Doctor?

A: Yes.

Q: Is it possible that you may have made some sort of comment of suggestion to Jennifer during therapy that led her to believe her symptoms were the result of sexual abuse as a child?

A: No, no such comment was made. I followed the Guidelines and did not make any suggestions to Jennifer that she had been abused.

Q: Now Dr. Dunbar, are you aware of the research regarding false memory syndrome and implantation?

A: Well, of course. Any respectable clinician practicing hypnosis keeps up with the research.

Q: Is it true that these studies have demonstrated the ability of the researcher to implant false memories, such as being lost in the mall at a young age, which never really occurred?

A: Yes, I recall such studies and I also recall their lack of ecological validity. Memories of sexual abuse are far more traumatic then a memory of being lost in a shopping mall. It would be unethical for a researcher to attempt to implant memories of sexual abuse; 
however, studies that attempt to implant memories of being lost as a child and then compare the outcome to actual cases of repressed sexual abuse lack ecological validity and cannot be generalized to such cases as Jennifer's.

Q: But in these studies, did results show that the researchers were able to implant these false memories into some participants, who then believed and were confident the events really happened?

A: Yes, a small portion of participants did later recall the false memory implanted by the researcher as being an actual memory.

Q: Dr. Dunbar, is there any real sound empirical evidence supporting whether or not traumatic memories can truly be repressed and recovered many years later?

A: Well, no not really... but there is also no sound empirical evidence proving that traumatic memories cannot be repressed and recovered many years later!

Dr. Dennehy: No further questions your honor.

\section{Condition 3: Hypnosis/Expert Defense}

Direct Examination of the Victim

JUDGE: Today we are hearing evidence in the case of Jennifer Riley v. Robert Smith.

The defendant, Mr. Smith is accused of sexually abusing the Plaintiff, Ms. Riley, 20 years prior to this trial. Mr. Morin (plaintiff's attorney) would you like to call your first witness?

A: Yes, your honor. I would like to call Jennifer Riley to the stand.

OATH: Do you solemnly swear you will tell the truth and nothing but the truth, so help you? 
A: Yes.

Q: Please state your full name?

A: My name is Jennifer Riley.

Q: What brings you to court today Jennifer?

A: I am filing suit for damages endured as a result of repeated sexual abuse.

Q: When did this abuse occur Jennifer?

A: Twenty years ago when I was 10 years old.

Q: Who is the person that abused you when you were such a young child?

A: That man (points to the defendant), my uncle Robert.

Q: And why did it take 20 years for you to file charges against Robert?

A: I was not aware of the childhood abuse until I recovered the memories recently in therapy through the process of hypnosis with Dr. Dunbar. My memories were deeply repressed and I had no awareness of the abuse.

Q: Why did you seek therapy Jennifer?

A: For as long as I can remember, I have experienced intense psychological symptoms of depression and anxiety. The depression and distress has been so severe that it has affected my work, intimate and personal relationships, and everyday life. Some days are so bad I cannot even get out of bed. My distrust of others has prevented any sort of long-term relationships and there are times when I feel completely hopeless and helpless. Q: You said you recovered the abuse through hypnosis in therapy. Tell me about that. A: Among other relaxation techniques, Dr. Dunbar offered hypnosis and regression therapy, which assists in returning to a childhood state to help heal symptoms and relieve 
distress. Through hypnosis, I uncovered vivid and repetitive memories of sexual abuse perpetrated by Uncle Robert in the summer of 1988, when I was 10 years old.

Q: As painful as it is, can you please describe the memories you uncovered for the jury. A: That summer I stayed at my aunt and uncles during the weeks while my parents were at work. During this time, Uncle Robert would take me into the cabana by the swimming pool in the backyard and force me to remove my clothes. He would order me to perform oral sex on him and then would force me to have intercourse with him. He covered my mouth to prevent my screams of pain and after it was done, he made me get dressed and said if I ever told anyone, bad things would happen to my parents and I.

Q. At any point during therapy, did Dr. Dunbar suggest your symptoms may have been the result of childhood sexual abuse?

A: No. Dr. Dunbar never once made any suggestions or accusations.

Q. When did the issue of sexual abuse arise in therapy?

A. It was not until I recovered the memories with the aid of hypnosis and discussed them afterwards with Dr. Dunbar, that we began to talk about the possible implications. Q: Did Dr. Dunbar ask you about any abuse after the hypnosis sessions?

A: No. I recalled the memories and was mortified. I brought them to Dr. Dunbar's attention and we began to work through my psychological problems that I now knew were the result of the childhood abuse.

Q: How long would you say you have suffered the ramifications of the abuse committed against you by the defendant? 
A: My whole life has been plagued by depression and distress. Even presently, I still suffer from residual symptoms of the abusive memories. The medical bills and therapy sessions are numerous and he (the defendant) is to blame.

Mr. Morin: No further questions your honor.

Cross-Examination of the Victim

JUDGE: Mr. Dennehy (defense attorney), would you like to question the witness?

Mr. Dennehy: Yes, thank you your honor.

Q: Good afternoon, Jennifer, I am Mr. Dennehy, the defense attorney in this case. I would like to ask you a few questions regarding your memories of abuse. When did you say you began attending therapy with Dr. Dunbar?

A: About one year ago.

Q: And how long into therapy were you before hypnosis was utilized to help relieve any symptoms?

A: About 3 or 4 months in.

Q: Why was hypnosis used in your therapy sessions after that point?

A: My symptoms were severe and persistent, so Dr. Dunbar offered hypnosis as an alternative technique to try and help with symptom relief.

Q: So Dr. Dunbar suggested you use hypnosis to uncover memories?

A: No. She offered hypnosis as an option and I accepted.

Q: And with hypnosis you uncovered these vivid memories of abuse?

A: Yes. After hypnosis was used, I was able to describe in detail these memories of abuse.

Q: Did you have any recollections of abuse before the hypnosis was used? 
A: No, the memories were repressed.

Q: Did you remember spending summers at your aunt and uncles?

A: Yes I did.

Q: SO you remember being at your aunt and uncles in the summer as a child, but you do not remember any instances of abuse prior to hypnosis in therapy?

A: Yes, that's correct.

Q: Did you ever consider that these alleged vivid memories, were nothing more than imagined instances, implanted during hypnosis in therapy?

A: No, they are real memories.

Q: But if you can remember being there in the summer, don't you think you would remember such abuse?

A: My memories were deeply repressed. They are traumatic real memories that I repressed and recovered in therapy with the help of hypnosis. This does not make my memories any less real.

Q: You have been experiencing psychological symptoms for a while Jennifer?

A: Yes, for as long as I can remember.

Q: And I certain that you would give anything to figure out the origin or cause of those symptoms, for relief?

A: Well, yes of course.

Q: Is it possible, that you wanted answers so badly that your mind created the memories of abuse as a way to cope with your symptoms, and recalled them after hypnosis as vivid memories? 
A: No. That is not what happened. Hypnosis helped me remember what already happened. Uncle Robert took my innocence. He abused me when I was just 10 years old and the truth will finally come out.

Mr. Dennehy: No further questions your honor.

Direct Examination of the Defense Expert

Q: Please state your name for the court.

A: My name is Dr. William Springs.

Q: Dr. Springs, what are your qualifications for offering expert testimony on the psychology of repressed memory and hypnosis?

A: I earned my undergraduate degree and went on to obtain a Ph.D. in psychology. I have conducted scientific research on human memory including repressed memory, suggestibility, and false memory for over 20 years. I have authored 9 book chapters and approximately 50 scientific articles on repressed memory and an additional 15 articles concerning hypnosis and suggestibility. I have conducted research under and alongside of Elizabeth Loftus and I have served as an expert witness in over 45 trials.

Q: Dr. Springs, tell us how human memory works.

A: Human memory is a complex cognitive process involving three distinct stages. At the first stage, information is perceived and encoded into memory. At the second stage, encoded information is stored in memory. At the third stage, stored information is retrieved from memory, such as when a witness is asked to recall information about a crime. Memory is vulnerable at each of these stages. There are factors that can influence what information a witness or victim perceives or encodes into memory. There are factors that can influence the accuracy of memories. 
Q: Can memories, in fact, be repressed?

A: The debate over repressed memory stems less from whether or not memories can actually be repressed and more from whether these repressed memories, once retrieved, are truly accurate.

Q: Can you go into more detail about that Dr. Springs.

A: Well, human memory is greatly influenced by expectations and when memories are incomplete, people have a tendency to fill in the gaps by creating images of what they believe or someone else believes must have happened or should have happened. If an individual alleges to have repressed a memory, such as child abuse, and is currently experiencing psychological distress, they may come to believe they experienced things that may have never happened as a way of explaining and coping with their current mental health deterioration.

Q: What research are you aware of concerning repressed memories and the false memory debate?

A: Studies conducted by Loftus, myself, and other researchers in this area demonstrate that false memories can indeed be planted into participants' unconscious and result in the individual embracing the false memory as if it truly occurred. Even more dangerous, the individuals not only believed the false memory was accurate, but were presented with increased confidence that the event actually occurred in their past. It can become almost impossible to convince the individual that the memory is indeed false, and they may continue to believe the implanted false memory. This is not to say that traumatic memories cannot be repressed and later retrieved. This research attempts to show that it 
may be difficult to determine true memories from false ones, once repressed memories are retrieved.

Q: In the present case, Jennifer retrieved her alleged repressed memories through the process of hypnosis. In your research and practice, what have you come to believe about hypnosis?

A: Hypnosis does not help people remember more accurately and during hypnosis the questions asked by the hypnotist can serve as suggestions that create expectations concerning what the person could have experienced versus what they actually experienced. A person under hypnosis is highly suggestible and therefore, even the slightest cue from the therapist could result in the client embracing the suggestion as a true memory, even if it is in deed, false.

Q: Is there a risk of false memory implantation with hypnosis, Dr. Springs?

A: Most definitely. The therapist may have a notion that the individual's presenting psychological symptoms and distress may have been the results of childhood sexual abuse. They may ask leading questions and offers suggestions during hypnosis, thus implanting false memories into the person's unconscious. This is not to say that some individuals may have actually been sexually abused as a child; however, some clinicians may automatically link certain adult symptoms to childhood sexual abuse and tailor hypnosis to discover such abuse, when it may have never occurred. This becomes an issue when lawsuits and charges are brought against alleged perpetrators, who are truly innocent of the crime.

Q: And what can become of these implanted memories? 
A: The hypnotized individual can come to believe that they experiences things that never happened and that these memories were just repressed. Such a process may have occurred in the present case and in such a situation, it is difficult to know which parts of the memories are accurate and credible, and which may have been fabricated through the process of hypnosis.

Mr. Dennehy: Thank you Dr. Springs. I have no further questions your honor.

\section{$\underline{\text { Cross-Examination of Defense Expert }}$}

JUDGE: Mr. Morin, would you like to question the witness?

Mr. Morin: Yes, thank you, your honor.

Q: Dr. Springs, you say that you have testified as an expert in how many trials?

A: Approximately 45 or so.

Q: And of these 45 or so trials, how many times have you testified on behalf of the prosecution?

A: I have never testified on behalf of the prosecution.

Q: So it would seem you solely testify on behalf of the defense?

A: Yes, I suppose that would be true.

Q: Was there ever a time when you testified in defense of a defendant on trial for sexual abuse that was proven guilty without a doubt?

A: Yes, I believe that I have.

Q: So it seems you will testify as an expert for the defense no matter what the circumstances?

A: Well, I wouldn't say that but...

Q: Yes or no, Dr. Springs. 
A: Well, yes I only have testified for the defense.

Q: Now, you base most of your claims about repressed memories off the research in that area?

A: Yes, that is correct; my research, the research of Loftus, and others in the field.

Q: And what have you found?

A: False memories can be implanted and later retrieved as if they were true and accurate memories.

Q: What sort of memories did you implant into the participants unconscious?

A: We would suggest that the participants were lost as a child, or that they were very sick as a child. Things such as this, and some participants later recalled the false memory as if it truly happened and were confident in the memory.

Q: Would you say it is valid to compare the harmless memory of being lost as a child to the extremely traumatic memory of being sexually abused?

A: The results from the study are meant to support that memories can indeed be implanted.

Q: Have you done research supporting that memories of sexual abuse can be implanted? A: Well, no we have not.

Q: So if there is no research to support that memories of sexual abuse can be implanted, then is it possible that Jennifer's memories are true and not implanted during hypnosis?

A: Well, it is possible but...

Q: Yes or no, Dr. Springs?

A: Yes, it is possible.

Q: You stated that under hypnosis, an individual is highly suggestible? 
A: Yes, I believe I did.

Q: Are you aware of the Guidelines clinicians are to follow when conducting hypnosis, in order for the information obtained to be uncontaminated and free of suggestion?

A: Yes, I am aware of the Guidelines.

Q: And are you aware that Dr. Dunbar (Jennifer's therapist) followed the Guidelines extremely closely in her practice?

A: Yes, I am aware of this.

Q: So is it possible that while Dr. Dunbar was following the Guidelines and performing hypnosis, Jennifer recovered memories she had repressed long ago free of suggestion and contamination?

A: Well, if the Guidelines were strictly adhered to, then I guess it is possible.

Mr. Morin: No further questions your honor.

\section{Condition 4: Hypnosis/Both Experts}

Direct Examination of the Victim

JUDGE: Today we are hearing evidence in the case of Jennifer Riley v. Robert Smith. The defendant, Mr. Smith is accused of sexually abusing the Plaintiff, Ms. Riley, 20 years prior to this trial. Mr. Morin (plaintiff's attorney) would you like to call your first witness?

A: Yes, your honor. I would like to call Jennifer Riley to the stand.

OATH: Do you solemnly swear you will tell the truth and nothing but the truth, so help you?

A: Yes. 
Q: Please state your full name?

A: My name is Jennifer Riley.

Q: What brings you to court today Jennifer?

A: I am filing suit for damages endured as a result of repeated sexual abuse.

Q: When did this abuse occur Jennifer?

A: Twenty years ago when I was 10 years old.

Q: Who is the person that abused you when you were such a young child?

A: That man (points to the defendant), my uncle Robert.

Q: And why did it take 20 years for you to file charges against Robert?

A: I was not aware of the childhood abuse until I recovered the memories recently in therapy through the process of hypnosis with Dr. Dunbar. My memories were deeply repressed and I had no awareness of the abuse.

Q: Why did you seek therapy Jennifer?

A: For as long as I can remember, I have experienced intense psychological symptoms of depression and anxiety. The depression and distress has been so severe that it has affected my work, intimate and personal relationships, and everyday life. Some days are so bad I cannot even get out of bed. My distrust of others has prevented any sort of long-term relationships and there are times when I feel completely hopeless and helpless. Q: You said you recovered the abuse through hypnosis in therapy. Tell me about that. A: Among other relaxation techniques, Dr. Dunbar offered hypnosis and regression therapy, which assists in returning to a childhood state to help heal symptoms and relieve distress. Through hypnosis, I uncovered vivid and repetitive memories of sexual abuse perpetrated by Uncle Robert in the summer of 1988, when I was 10 years old. 
Q: As painful as it is, can you please describe the memories you uncovered for the jury. A: That summer I stayed at my aunt and uncles during the weeks while my parents were at work. During this time, Uncle Robert would take me into the cabana by the swimming pool in the backyard and force me to remove my clothes. He would order me to perform oral sex on him and then would force me to have intercourse with him. He covered my mouth to prevent my screams of pain and after it was done, he made me get dressed and said if I ever told anyone, bad things would happen to my parents and I.

Q. At any point during therapy, did Dr. Dunbar suggest your symptoms may have been the result of childhood sexual abuse?

A: No. Dr. Dunbar never once made any suggestions or accusations.

Q. When did the issue of sexual abuse arise in therapy?

A. It was not until I recovered the memories with the aid of hypnosis and discussed them afterwards with Dr. Dunbar, that we began to talk about the possible implications. Q: Did Dr. Dunbar ask you about any abuse after the hypnosis sessions?

A: No. I recalled the memories and was mortified. I brought them to Dr. Dunbar's attention and we began to work through my psychological problems that I now knew were the result of the childhood abuse.

Q: How long would you say you have suffered the ramifications of the abuse committed against you by the defendant?

A: My whole life has been plagued by depression and distress. Even presently, I still suffer from residual symptoms of the abusive memories. The medical bills and therapy sessions are numerous and he (the defendant) is to blame.

Mr. Morin: No further questions your honor. 


\section{$\underline{\text { Cross-Examination of the Victim }}$}

JUDGE: Mr. Dennehy (defense attorney), would you like to question the witness?

Mr. Dennehy: Yes, thank you your honor.

Q: Good afternoon, Jennifer, I am Mr. Dennehy, the defense attorney in this case. I would like to ask you a few questions regarding your memories of abuse. When did you say you began attending therapy with Dr. Dunbar?

A: About one year ago.

Q: And how long into therapy were you before hypnosis was utilized to help relieve any symptoms?

A: About 3 or 4 months in.

Q: Why was hypnosis used in your therapy sessions after that point?

A: My symptoms were severe and persistent, so Dr. Dunbar offered hypnosis as an alternative technique to try and help with symptom relief.

Q: So Dr. Dunbar suggested you use hypnosis to uncover memories?

A: No. She offered hypnosis as an option and I accepted.

Q: And with hypnosis you uncovered these vivid memories of abuse?

A: Yes. After hypnosis was used, I was able to describe in detail these memories of abuse.

Q: Did you have any recollections of abuse before the hypnosis was used?

A: No, the memories were repressed.

Q: Did you remember spending summers at your aunt and uncles?

A: Yes I did. 
Q: SO you remember being at your aunt and uncles in the summer as a child, but you do not remember any instances of abuse prior to hypnosis in therapy?

A: Yes, that's correct.

Q: Did you ever consider that these alleged vivid memories, were nothing more than imagined instances, implanted during hypnosis in therapy?

A: No, they are real memories.

Q: But if you can remember being there in the summer, don't you think you would remember such abuse?

A: My memories were deeply repressed. They are traumatic real memories that I repressed and recovered in therapy with the help of hypnosis. This does not make my memories any less real.

Q: You have been experiencing psychological symptoms for a while Jennifer?

A: Yes, for as long as I can remember.

Q: And I certain that you would give anything to figure out the origin or cause of those symptoms, for relief?

A: Well, yes of course.

Q: Is it possible, that you wanted answers so badly that your mind created the memories of abuse as a way to cope with your symptoms, and recalled them after hypnosis as vivid memories?

A: No. That is not what happened. Hypnosis helped me remember what already happened. Uncle Robert took my innocence. He abused me when I was just 10 years old and the truth will finally come out.

Mr. Dennehy: No further questions your honor. 


\section{Direct Examination of Plaintiff Expert}

Q: Please state your name for the court.

A: My name is Dr. Rachel Dunbar.

Q: Dr. Dunbar, would you please describe your credentials for the court?

A: I earned my undergraduate degree at State University and then earned a Ph. D. in clinical psychology. I am a clinician and researcher specializing in repressed memory, hypnosis, and counseling. I am also a certified clinical hypnotherapist by the American Institute of Hypnotherapy and have nearly 25 years of practical experience. I practiced under Martin Orne in England for many years and have taught courses at the undergraduate and graduate level. I am a member of the American Association of Professional Hypnotherapists, author of 15 books and over 50 articles for prestigious psychological journals, and both attend and conduct lectures on the clinical uses of hypnosis.

Q: Was Jennifer Riley one of your clients in therapy?

A: Jennifer came to my office seeking therapy for a number of reasons. She was suffering from long-term depression and anxiety. She was having trouble sleeping, eating, at work, at home, and in her relationships.

Q: When did you offer hypnosis as an option?

A: About 3 or 4 months into therapy, I offered hypnosis as an option to help relieve some of Jennifer's symptoms. With hypnosis age regression and/or relaxation, the client has access to unconscious memories and motives, which may be the cause of present psychological symptoms. Jennifer was a fitting candidate for hypnosis. Q: Did you ever force Jennifer to partake in hypnosis? 
A: Never. The process was voluntary and Jennifer was eager to try the procedure. Q: How does hypnosis work Dr. Dunbar?

A: Well, during hypnosis the client is coached into a state of deep relaxation, using eyefixation or counting techniques. Once in this relaxed state, clients are able to relive prior experiences, uncover repressed memories, and have access to the unconscious mind. Once awakened from hypnosis, the client may begin to recall events they had no recollection of prior to hypnosis. These repressed memories could have some influence on their present psychological distress.

Q: Describe for the court what you mean by repressed memories.

A: The human mind is akin to a videotape recorder that stores away almost all experiences. Traumatic experiences, such as sexual abuse, can often be repressed or forced into the unconscious mind. An individual may have no recollection of such traumatic memories. Repressed memories can be spontaneously recovered or can be recovered through different processes, one being hypnosis. Once the memory is brought into the conscious mind, it is no longer forgotten or repressed.

Q: Are you aware of the Guidelines set forth regarding hypnosis in therapy and admissibility in court?

A: Yes, I am extremely aware of such guidelines and always follow them in my practice. Clients are very suggestible under hypnosis and I would not want to do anything that would interfere with their experience or implant memories that did not occur. Q: Did you, at any point in time, suggest to Jennifer that she had been sexually abused as a child?

A: No, I did not make any such suggestions. 
Q: When was the subject of abuse brought about in therapy?

A: After some hypnosis sessions, Jennifer came to therapy and disclosed the memories of abuse to me. We began discussing these memories and Jennifer began to link the memories to her current distress.

Q: Did you ever once try to implant false memories of abuse or alter Jennifer's memories in any way with the use of hypnosis?

A: Absolutely not.

Q: Dr. Dunbar, do you believe that Jennifer's repressed memories of abuse represent the true state of affairs and can be considered credible?

A: It is my opinion that Jennifer's memories are both accurate and credible. I believe they are vivid representations of the true state of affairs 20 years ago.

Mr. Morin: Thank you. No further questions your honor.

\section{$\underline{\text { Cross-Examination of Prosecution Expert }}$}

JUDGE: Mr. Dennehy, would you like to question the witness?

Mr. Dennehy: Yes, thank you, your honor.

Q: Dr. Dunbar, you discussed the process of hypnosis in therapy earlier, remarking that the client may become highly suggestible?

A: Yes, that is correct. In such a state of deep relaxation, clients are more vulnerable to suggestions.

Q: Would you say that the Plaintiff, Jennifer, was in such a state of deep relaxation during your hypnosis session?

A: Well, yes, I would say Jennifer reached that relaxation state.

Q: So, Jennifer was in a state of relaxation where she was also highly suggestible? 
A: That is correct.

Q: How long have you practiced hypnosis doctor?

A: For over 25 years.

Q: And in those 25 years have you ever made suggestions to a client during hypnotherapy?

A: Well, there are different types of suggestions...

Q: Yes or no Doctor?

A: Yes.

Q: Is it possible that you may have made some sort of comment of suggestion to Jennifer during therapy that led her to believe her symptoms were the result of sexual abuse as a child?

A: No, no such comment was made. I followed the Guidelines and did not make any suggestions to Jennifer that she had been abused.

Q: Now Dr. Dunbar, are you aware of the research regarding false memory syndrome and implantation?

A: Well, of course. Any respectable clinician practicing hypnosis keeps up with the research.

Q: Is it true that these studies have demonstrated the ability of the researcher to implant false memories, such as being lost in the mall at a young age, which never really occurred?

A: Yes, I recall such studies and I also recall their lack of ecological validity. Memories of sexual abuse are far more traumatic then a memory of being lost in a shopping mall. It would be unethical for a researcher to attempt to implant memories of sexual abuse; 
however, studies that attempt to implant memories of being lost as a child and then compare the outcome to actual cases of repressed sexual abuse lack ecological validity and cannot be generalized to such cases as Jennifer's.

Q: But in these studies, did results show that the researchers were able to implant these false memories into some participants, who then believed and were confident the events really happened?

A: Yes, a small portion of participants did later recall the false memory implanted by the researcher as being an actual memory.

Q: Dr. Dunbar, is there any real sound empirical evidence supporting whether or not traumatic memories can truly be repressed and recovered many years later?

A: Well, no not really... but there is also no sound empirical evidence proving that traumatic memories cannot be repressed and recovered many years later!

Dr. Dennehy: No further questions your honor.

Direct Examination of the Defense Expert

Q: Please state your name for the court.

A: My name is Dr. William Springs.

Q: Dr. Springs, what are your qualifications for offering expert testimony on the psychology of repressed memory and hypnosis?

A: I earned my undergraduate degree and went on to obtain a Ph.D. in psychology. I have conducted scientific research on human memory including repressed memory, suggestibility, and false memory for over 20 years. I have authored 9 book chapters and approximately 50 scientific articles on repressed memory and an additional 15 articles 
concerning hypnosis and suggestibility. I have conducted research under and alongside of Elizabeth Loftus and I have served as an expert witness in over 45 trials.

Q: Dr. Springs, tell us how human memory works.

A: Human memory is a complex cognitive process involving three distinct stages. At the first stage, information is perceived and encoded into memory. At the second stage, encoded information is stored in memory. At the third stage, stored information is retrieved from memory, such as when a witness is asked to recall information about a crime. Memory is vulnerable at each of these stages. There are factors that can influence what information a witness or victim perceives or encodes into memory. There are factors that can influence the accuracy of memories.

Q: Can memories, in fact, be repressed?

A: The debate over repressed memory stems less from whether or not memories can actually be repressed and more from whether these repressed memories, once retrieved, are truly accurate.

Q: Can you go into more detail about that Dr. Springs.

A: Well, human memory is greatly influenced by expectations and when memories are incomplete, people have a tendency to fill in the gaps by creating images of what they believe or someone else believes must have happened or should have happened. If an individual alleges to have repressed a memory, such as child abuse, and is currently experiencing psychological distress, they may come to believe they experienced things that may have never happened as a way of explaining and coping with their current mental health deterioration. 
Q: What research are you aware of concerning repressed memories and the false memory debate?

A: Studies conducted by Loftus, myself, and other researchers in this area demonstrate that false memories can indeed be planted into participants' unconscious and result in the individual embracing the false memory as if it truly occurred. Even more dangerous, the individuals not only believed the false memory was accurate, but were presented with increased confidence that the event actually occurred in their past. It can become almost impossible to convince the individual that the memory is indeed false, and they may continue to believe the implanted false memory. This is not to say that traumatic memories cannot be repressed and later retrieved. This research attempts to show that it may be difficult to determine true memories from false ones, once repressed memories are retrieved.

Q: In the present case, Jennifer retrieved her alleged repressed memories through the process of hypnosis. In your research and practice, what have you come to believe about hypnosis?

A: Hypnosis does not help people remember more accurately and during hypnosis the questions asked by the hypnotist can serve as suggestions that create expectations concerning what the person could have experienced versus what they actually experienced. A person under hypnosis is highly suggestible and therefore, even the slightest cue from the therapist could result in the client embracing the suggestion as a true memory, even if it is in deed, false.

Q: Is there a risk of false memory implantation with hypnosis, Dr. Springs? 
A: Most definitely. The therapist may have a notion that the individual's presenting psychological symptoms and distress may have been the results of childhood sexual abuse. They may ask leading questions and offers suggestions during hypnosis, thus implanting false memories into the person's unconscious. This is not to say that some individuals may have actually been sexually abused as a child; however, some clinicians may automatically link certain adult symptoms to childhood sexual abuse and tailor hypnosis to discover such abuse, when it may have never occurred. This becomes an issue when lawsuits and charges are brought against alleged perpetrators, who are truly innocent of the crime.

Q: And what can become of these implanted memories?

A: The hypnotized individual can come to believe that they experiences things that never happened and that these memories were just repressed. Such a process may have occurred in the present case and in such a situation, it is difficult to know which parts of the memories are accurate and credible, and which may have been fabricated through the process of hypnosis.

Mr. Dennehy: Thank you Dr. Springs. I have no further questions your honor. Cross-Examination of Defense Expert

JUDGE: Mr. Morin, would you like to question the witness?

Mr. Morin: Yes, thank you, your honor.

Q: Dr. Springs, you say that you have testified as an expert in how many trials?

A: Approximately 45 or so.

Q: And of these 45 or so trials, how many times have you testified on behalf of the prosecution? 
A: I have never testified on behalf of the prosecution.

Q: So it would seem you solely testify on behalf of the defense?

A: Yes, I suppose that would be true.

Q: Was there ever a time when you testified in defense of a defendant on trial for sexual abuse that was proven guilty without a doubt?

A: Yes, I believe that I have.

Q: So it seems you will testify as an expert for the defense no matter what the circumstances?

A: Well, I wouldn't say that but...

Q: Yes or no, Dr. Springs.

A: Well, yes I only have testified for the defense.

Q: Now, you base most of your claims about repressed memories off the research in that area?

A: Yes, that is correct; my research, the research of Loftus, and others in the field.

Q: And what have you found?

A: False memories can be implanted and later retrieved as if they were true and accurate memories.

Q: What sort of memories did you implant into the participants unconscious?

A: We would suggest that the participants were lost as a child, or that they were very sick as a child. Things such as this, and some participants later recalled the false memory as if it truly happened and were confident in the memory.

Q: Would you say it is valid to compare the harmless memory of being lost as a child to the extremely traumatic memory of being sexually abused? 
A: The results from the study are meant to support that memories can indeed be implanted.

Q: Have you done research supporting that memories of sexual abuse can be implanted? A: Well, no we have not.

Q: So if there is no research to support that memories of sexual abuse can be implanted, then is it possible that Jennifer's memories are true and not implanted during hypnosis? A: Well, it is possible but... Q: Yes or no, Dr. Springs?

A: Yes, it is possible.

Q: You stated that under hypnosis, an individual is highly suggestible?

A: Yes, I believe I did.

Q: Are you aware of the Guidelines clinicians are to follow when conducting hypnosis, in order for the information obtained to be uncontaminated and free of suggestion?

A: Yes, I am aware of the Guidelines.

Q: And are you aware that Dr. Dunbar testified to following the Guidelines extremely closely in her practice?

A: Yes, I am aware of this.

Q: So is it possible that while Dr. Dunbar was following the Guidelines and performing hypnosis, Jennifer recovered memories she had repressed long ago free of suggestion and contamination?

A: Well, if the Guidelines were strictly adhered to, then I guess it is possible. Mr. Morin: No further questions your honor. 


\section{Condition 5: No Hypnosis/No Experts}

\section{Direct Examination of the Victim}

JUDGE: Today we are hearing evidence in the case of Jennifer Riley v. Robert Smith.

The defendant, Mr. Smith is accused of sexually abusing the Plaintiff, Ms. Riley, 20

years prior to this trial. Mr. Morin (plaintiff's attorney) would you like to call your first witness?

A: Yes, your honor. I would like to call Jennifer Riley to the stand.

OATH: Do you solemnly swear you will tell the truth and nothing but the truth, so help you?

A: Yes.

Q: Please state your full name?

A: My name is Jennifer Riley.

Q: What brings you to court today Jennifer?

A: I am filing suit for damages endured as a result of repeated sexual abuse.

Q: When did this abuse occur Jennifer?

A: Twenty years ago when I was 10 years old.

Q: Who is the person that abused you when you were such a young child?

A: That man (points to the defendant), my uncle Robert.

Q: And why did it take 20 years for you to file charges against Robert?

A: I have carried the memories of the abuse with me since I was a child. My uncle threatened me back then that if I ever told anyone, my parents and I would suffer for it. In the last year or so, I have been regularly attending therapy with Dr. Dunbar to treat depression and anxiety. I have had these symptoms for as long as I can remember. 
Therapy was the first time I disclosed the abuse to another person and began to discover that my current depression and anxiety could be the result of residual distress from the abuse I kept hidden so many years.

Q: You attended therapy to treat depression and anxiety, Jennifer. Tell me about that. A: For as long as I can remember, I have experienced intense psychological symptoms of depression and anxiety. The depression and distress has been so severe that it has affected my work, intimate and personal relationships, and everyday life. Some days are so bad I cannot even get out of bed. My distrust of others has prevented any sort of long-term relationships and there are times when I feel completely hopeless and helpless. I kept the abuse hidden for so long; it ate away at me inside.

Q: You said you remembered the abuse throughout the years and recently connected it to your current symptoms in therapy. Tell me about that.

A: Through talking therapy, and relaxation, I became comfortable enough with Dr. Dunbar to disclose my horrible secret. For so long, I had blamed myself and felt ashamed and embarrassed for what he did to me. Dr. Dunbar helped me realize that in order to relieve my symptoms, I needed to face my fears and my past. We began to discuss the abuse and it was then, that I began to realize my depression and anxiety was the direct result of the abuse and keeping it hidden all these years.

Q: As painful as it is, can you please describe these memories of abuse for the jury. A: The summer of 1988, I stayed at my aunt and uncles during the weeks while my parents were at work. During this time, Uncle Robert would take me into the cabana by the swimming pool in the backyard and force me to remove my clothes. He would order me to perform oral sex on him and then would force me to have intercourse with him. He 
covered my mouth to prevent my screams of pain and after it was done, he made me get dressed and said if I ever told anyone, bad things would happen to my parents and I; that we would suffer. I never told a soul, not even my best friend.

Q. At any point during therapy, did Dr. Dunbar suggest your symptoms of depression and anxiety may have been the result of childhood sexual abuse?

A: No. Dr. Dunbar never once made any suggestions or accusations.

Q. When did the issue of sexual abuse arise in therapy?

A. We would frequently talk about past relationships and family, but I was afraid to bring up the abuse. Once I was comfortable with Dr. Dunbar, I disclosed my memories of sexual abuse to her. Only then did we begin to discuss the horrific memories and link them to my current problems. It was at that moment that I began to progress in therapy toward symptom relief, once I stopped blaming myself and feeling ashamed.

Q: How long would you say you have suffered the ramifications of the abuse committed against you by the defendant?

A: My whole life has been plagued by depression and distress. Even presently, I still suffer from residual symptoms of the abusive memories. The medical bills and therapy sessions are numerous and he (the defendant) is to blame. Through therapy, I have realized that I was a child then and it was not my fault. I am an adult now and not afraid to speak out anymore. He deserves to be punished for what he did to me. I was only a child, a defenseless child.

Mr. Morin: No further questions your honor.

\section{Cross-Examination of the Victim}

JUDGE: Mr. Dennehy (defense attorney), would you like to question the witness? 
Mr. Dennehy: Yes, thank you your honor.

Q: Good afternoon, Jennifer, I am Mr. Dennehy, the defense attorney in this case. I would like to ask you a few questions regarding your memories of abuse. When did you say you began attending therapy with Dr. Dunbar?

A: About one year ago.

Q: And how long into therapy were you before you disclosed your memories of abuse?

A: About 3 or 4 months in.

Q: Why had the memories not come up until this point?

A: As I said, I was not ready to share such painful memories and I was ashamed.

Q: Did Dr. Dunbar ever have you think back to childhood memories?

A: Yes. We would discuss my childhood and past often.

Q: Was there ever any suggestions made that your current symptoms seem compatible with those seen in abuse survivors?

A: No. Dr. Dunbar never suggested abuse. We merely talked about the past.

Q: How clear would you say the memories you have of the alleged abuse are?

A: I remember it as though it happened yesterday. I can still picture that cabana and how afraid I was every time I went to their house.

Q: Do you remember the exact dates the abuse occurred on?

A: No, just the summer of 1988 .

Q: Do remember the exact time of day the abuse occurred? Exactly what you were doing before and after?

A: Well, it was in the afternoon sometime... and no, I just remember his bringing me to the cabana. 
Q: Do you remember what you were doing on June 15, 2001?

A: Well, no not that exact date but I know what I did that summer.

Q: So it is fair to say that your memory of things is not exactly perfect?

A: Well, no, no one has a perfect memory.

Q: So, maybe your memories for the events that summer are less than perfect?

A: No. I know what happened that summer and he knows what happened that summer.

He abused me and I remember it clear as day because I replay it in my mind everyday since the times it happened. I was never the same after that summer.

Q: You have been experiencing psychological symptoms for a while Jennifer?

A: Yes, for as long as I can remember.

Q: And I certain that you would give anything to figure out the origin or cause of those symptoms, for relief?

A: Well, yes of course.

Q: Is it possible, that you wanted answers so badly that your mind created the memories of abuse as a way to cope with your symptoms?

A: No. That is not what happened. I have had these memories since I was 10 and they have not faded. Uncle Robert took my innocence. He abused me when I was just 10 years old and the truth will finally come out. I did not imagine this abuse and I did not make it up to fix my problems. This abuse caused my problems and I finally have the confidence to do something about it.

Mr. Dennehy: No further questions your honor. 


\section{Condition 6: No Hypnosis/Expert Plaintiff}

\section{Direct Examination of the Victim}

JUDGE: Today we are hearing evidence in the case of Jennifer Riley v. Robert Smith.

The defendant, Mr. Smith is accused of sexually abusing the Plaintiff, Ms. Riley, 20

years prior to this trial. Mr. Morin (plaintiff's attorney) would you like to call your first witness?

A: Yes, your honor. I would like to call Jennifer Riley to the stand.

OATH: Do you solemnly swear you will tell the truth and nothing but the truth, so help you?

A: Yes.

Q: Please state your full name?

A: My name is Jennifer Riley.

Q: What brings you to court today Jennifer?

A: I am filing suit for damages endured as a result of repeated sexual abuse.

Q: When did this abuse occur Jennifer?

A: Twenty years ago when I was 10 years old.

Q: Who is the person that abused you when you were such a young child?

A: That man (points to the defendant), my uncle Robert.

Q: And why did it take 20 years for you to file charges against Robert?

A: I have carried the memories of the abuse with me since I was a child. My uncle threatened me back then that if I ever told anyone, my parents and I would suffer for it. In the last year or so, I have been regularly attending therapy with Dr. Dunbar to treat depression and anxiety. I have had these symptoms for as long as I can remember. 
Therapy was the first time I disclosed the abuse to another person and began to discover that my current depression and anxiety could be the result of residual distress from the abuse I kept hidden so many years.

Q: You attended therapy to treat depression and anxiety, Jennifer. Tell me about that. A: For as long as I can remember, I have experienced intense psychological symptoms of depression and anxiety. The depression and distress has been so severe that it has affected my work, intimate and personal relationships, and everyday life. Some days are so bad I cannot even get out of bed. My distrust of others has prevented any sort of long-term relationships and there are times when I feel completely hopeless and helpless. I kept the abuse hidden for so long; it ate away at me inside.

Q: You said you remembered the abuse throughout the years and recently connected it to your current symptoms in therapy. Tell me about that.

A: Through talking therapy, and relaxation, I became comfortable enough with Dr. Dunbar to disclose my horrible secret. For so long, I had blamed myself and felt ashamed and embarrassed for what he did to me. Dr. Dunbar helped me realize that in order to relieve my symptoms, I needed to face my fears and my past. We began to discuss the abuse and it was then, that I began to realize my depression and anxiety was the direct result of the abuse and keeping it hidden all these years.

Q: As painful as it is, can you please describe these memories of abuse for the jury. A: The summer of 1988, I stayed at my aunt and uncles during the weeks while my parents were at work. During this time, Uncle Robert would take me into the cabana by the swimming pool in the backyard and force me to remove my clothes. He would order me to perform oral sex on him and then would force me to have intercourse with him. He 
covered my mouth to prevent my screams of pain and after it was done, he made me get dressed and said if I ever told anyone, bad things would happen to my parents and I; that we would suffer. I never told a soul, not even my best friend.

Q. At any point during therapy, did Dr. Dunbar suggest your symptoms of depression and anxiety may have been the result of childhood sexual abuse?

A: No. Dr. Dunbar never once made any suggestions or accusations.

Q. When did the issue of sexual abuse arise in therapy?

A. We would frequently talk about past relationships and family, but I was afraid to bring up the abuse. Once I was comfortable with Dr. Dunbar, I disclosed my memories of sexual abuse to her. Only then did we begin to discuss the horrific memories and link them to my current problems. It was at that moment that I began to progress in therapy toward symptom relief, once I stopped blaming myself and feeling ashamed.

Q: How long would you say you have suffered the ramifications of the abuse committed against you by the defendant?

A: My whole life has been plagued by depression and distress. Even presently, I still suffer from residual symptoms of the abusive memories. The medical bills and therapy sessions are numerous and he (the defendant) is to blame. Through therapy, I have realized that I was a child then and it was not my fault. I am an adult now and not afraid to speak out anymore. He deserves to be punished for what he did to me. I was only a child, a defenseless child.

Mr. Morin: No further questions your honor.

\section{Cross-Examination of the Victim}

JUDGE: Mr. Dennehy (defense attorney), would you like to question the witness? 
Mr. Dennehy: Yes, thank you your honor.

Q: Good afternoon, Jennifer, I am Mr. Dennehy, the defense attorney in this case. I would like to ask you a few questions regarding your memories of abuse. When did you say you began attending therapy with Dr. Dunbar?

A: About one year ago.

Q: And how long into therapy were you before you disclosed your memories of abuse?

A: About 3 or 4 months in.

Q: Why had the memories not come up until this point?

A: As I said, I was not ready to share such painful memories and I was ashamed.

Q: Did Dr. Dunbar ever have you think back to childhood memories?

A: Yes. We would discuss my childhood and past often.

Q: Was there ever any suggestions made that your current symptoms seem compatible with those seen in abuse survivors?

A: No. Dr. Dunbar never suggested abuse. We merely talked about the past.

Q: How clear would you say the memories you have of the alleged abuse are?

A: I remember it as though it happened yesterday. I can still picture that cabana and how afraid I was every time I went to their house.

Q: Do you remember the exact dates the abuse occurred on?

A: No, just the summer of 1988 .

Q: Do remember the exact time of day the abuse occurred? Exactly what you were doing before and after?

A: Well, it was in the afternoon sometime... and no, I just remember his bringing me to the cabana. 
Q: Do you remember what you were doing on June 15, 2001?

A: Well, no not that exact date but I know what I did that summer.

Q: So it is fair to say that your memory of things is not exactly perfect?

A: Well, no, no one has a perfect memory.

Q: So, maybe your memories for the events that summer are less than perfect?

A: No. I know what happened that summer and he knows what happened that summer.

He abused me and I remember it clear as day because I replay it in my mind everyday since the times it happened. I was never the same after that summer.

Q: You have been experiencing psychological symptoms for a while Jennifer?

A: Yes, for as long as I can remember.

Q: And I certain that you would give anything to figure out the origin or cause of those symptoms, for relief?

A: Well, yes of course.

Q: Is it possible, that you wanted answers so badly that your mind created the memories of abuse as a way to cope with your symptoms?

A: No. That is not what happened. I have had these memories since I was 10 and they have not faded. Uncle Robert took my innocence. He abused me when I was just 10 years old and the truth will finally come out. I did not imagine this abuse and I did not make it up to fix my problems. This abuse caused my problems and I finally have the confidence to do something about it.

Mr. Dennehy: No further questions your honor.

$\underline{\text { Direct Examination of Plaintiff Expert }}$

Q: Please state your name for the court. 
A: My name is Dr. Rachel Dunbar.

Q: Dr. Dunbar, would you please describe your credentials for the court?

A: I earned my undergraduate degree at State University and then earned a Ph. D. in clinical psychology. I am a clinician and researcher specializing in human memory and counseling. I have over 25 years of practical experience and have taught numerous courses at the undergraduate and graduate level. I am a member of the American Psychological Association author of 15 books, 9 book chapters, and over 50 articles for prestigious psychological journals. I have presented research at over 15 conferences and both attend and conduct lectures on clinical research and practice.

Q: Was Jennifer Riley one of your clients in therapy?

A: Jennifer came to my office seeking therapy for a number of reasons. She was suffering from long-term depression and anxiety. She was having trouble sleeping, eating, at work, at home, and in her relationships.

Q: About how far into therapy were you before Jennifer disclosed her memories of abuse?

A: About 3 or 4 months into therapy. Jennifer was reserved at the start of therapy and appeared unsure of herself and ashamed of her depression. I did my best to build rapport and make her feel as comfortable as possible in my office. We discussed her past relationships and childhood memories. It seemed that when she was comfortable, Jennifer told me about the abuse she endured 20 years earlier.

Q: Dr. Dunbar, you said you specialize in memory and counseling. Tell the court more about human memory. 
A: Memory is the retention of, and ability to recall, information, personal experiences, procedures, etc. Research on memory and neuroscience demonstrates support for the notion that a memory is a set of encoded neural connections. Encoding can take place in several parts of the brain, and thus, these neural connections can take place in several parts of the brain. The stronger these connections, the stronger the memory. Q: And what about memory recollection?

A: Recollection of an event can occur by a stimulus to any of the parts of the brain where a neural connection for the memory occurs. If a part of the brain is damaged, access to any neural data that was there is lost. On the other hand, if the brain is healthy and a person is fully conscious when experiencing some trauma, the likelihood that they will forget the event is nearly zero, unless they either are very young or experienced a brain injury.

Q: Is it possible that Jennifer experienced sexual abuse at the age of 10, never told anyone, and still clearly remembers the events today 20 years later?

A: Since Jennifer ascertains that the abuse occurred at 10 years old, it is possible that she formed long lasting memories of the experience and has remembered the abuse throughout the years, even if she did not discuss it with anyone until therapy. Q: Do you believe traumatic memories are harder to forget?

A: I support the claim that the more traumatic an experience, the more likely an individual is to remember it. Novel visual images, which would frequently accompany traumatic experiences, stimulate the hippocampus and left inferior prefrontal cortex and generally become part of long-term memory. 
Q: Did you, at any point in time, suggest to Jennifer that she had been sexually abused as a child?

A: No, I did not make any such suggestions.

Q: Did you ever suggest to Jennifer that her symptoms may be linked to or resulted from sexual abuse of any kind?

A: No, I did not. I have seen clients like Jennifer who are survivors of sexual abuse presenting with similar symptoms; however, I never once suggested to Jennifer that her symptoms must have been the result of such abuse.

Q: Do you believe that traumatic experiences such as childhood sexual abuse can cause psychological distress in adulthood similar to Jennifer's problems?

A: Yes, I do. When traumatic experiences occur in childhood they can cause immense psychological distress throughout the victim's life and into adulthood, even more so if the victim kept the experiences hidden from family members and friends. Childhood sexual abuse can cause problems with intimate relationships, work, daily life, and can result in the victim being ashamed, anxious, and depressed. Child victims tend to blame themselves for the abuse and carry this shame into adulthood, worsening their psychological trauma.

Q: Is it possible that Jennifer is experiencing depression and anxiety as a result of the sexual abuse she endured 20 years ago?

A: Yes, in my opinion it is definitely possible that the traumatic experiences of Jennifer's childhood have permeated her psychological well being and caused her symptoms. Q: Dr. Dunbar, do you believe that Jennifer's memories of abuse represent the true state of affairs and can be considered credible? 
A: It is my opinion that Jennifer's memories are both accurate and credible, and that her symptoms could be seen as a direct result of such memories and traumatic experiences. Mr. Morin: Thank you. No further questions your honor.

\section{$\underline{\text { Cross-Examination of Plaintiff Expert }}$}

JUDGE: Mr. Dennehy, would you like to question the witness?

Mr. Dennehy: Yes, thank you, your honor.

Q: Dr. Dunbar, you mentioned that Jennifer's symptoms fit the profile of an adult that had been sexually abused as a child?

A: Yes, I believe I said something like that.

Q: Would you say you spent a considerable amount of time talking about Jennifer's past relationships and childhood?

A: Well, yes, we explored Jennifer's life history and her childhood frequently in the beginning of therapy.

Q: Did you ever think that repetitively talking about childhood, may have suggested to Jennifer that her problems originated in childhood?

A: No... Lengthy discussions about the client's life are all part of building rapport and making the client comfortable. I never once suggested her psychological issues originated in childhood; thus, I would not think I led Jennifer to believe I expected anything from her.

Q: How long have you practiced as a clinician, Dr. Dunbar?

A: For over 25 years.

Q: And in those 25 years have you ever made suggestions to a client as to the origins of their psychological distress? 
A: Well, there are different types of suggestions...

Q: Yes or no Doctor?

A: Yes.

Q: Is it possible that you may have made some sort of comment of suggestion to Jennifer during therapy that led her to believe her symptoms were the result of sexual abuse as a child?

A: No, no such comment was made. I did not make any suggestions to Jennifer that she had been abused.

Q: Now Dr. Dunbar, are you aware of the research regarding memory and recollection? A: Well, of course. I specialize in that area.

Q: Are you aware of studies demonstrating the unreliability and inaccuracy of memory? A: Well, yes... no individual has a perfect memory.

Q: Are you aware of the research demonstrating that individuals construct memories after the fact and are susceptible to the suggestions from others to fill in gaps of the memory? A: Well that is one side of memory. I am also aware of the research demonstrating that after many years memories can remain intact and accurate.

Q: Is it possible that in a high state of psychological distress, an individual's original memory may become distorted?

A: Well, yes... I suppose that is possible.

Q: And would you say Jennifer was in a high state of distress when she came to you for therapy?

A: Well of course, she was suffering from anxiety and depression.

Dr. Dennehy: No further questions your honor. 


\section{Condition 7: No Hypnosis/Expert Defense}

\section{Direct Examination of the Victim}

JUDGE: Today we are hearing evidence in the case of Jennifer Riley v. Robert Smith.

The defendant, Mr. Smith is accused of sexually abusing the Plaintiff, Ms. Riley, 20

years prior to this trial. Mr. Morin (plaintiff's attorney) would you like to call your first witness?

A: Yes, your honor. I would like to call Jennifer Riley to the stand.

OATH: Do you solemnly swear you will tell the truth and nothing but the truth, so help you?

A: Yes.

Q: Please state your full name?

A: My name is Jennifer Riley.

Q: What brings you to court today Jennifer?

A: I am filing suit for damages endured as a result of repeated sexual abuse.

Q: When did this abuse occur Jennifer?

A: Twenty years ago when I was 10 years old.

Q: Who is the person that abused you when you were such a young child?

A: That man (points to the defendant), my uncle Robert.

Q: And why did it take 20 years for you to file charges against Robert?

A: I have carried the memories of the abuse with me since I was a child. My uncle threatened me back then that if I ever told anyone, my parents and I would suffer for it. In the last year or so, I have been regularly attending therapy with Dr. Dunbar to treat depression and anxiety. I have had these symptoms for as long as I can remember. 
Therapy was the first time I disclosed the abuse to another person and began to discover that my current depression and anxiety could be the result of residual distress from the abuse I kept hidden so many years.

Q: You attended therapy to treat depression and anxiety, Jennifer. Tell me about that. A: For as long as I can remember, I have experienced intense psychological symptoms of depression and anxiety. The depression and distress has been so severe that it has affected my work, intimate and personal relationships, and everyday life. Some days are so bad I cannot even get out of bed. My distrust of others has prevented any sort of long-term relationships and there are times when I feel completely hopeless and helpless. I kept the abuse hidden for so long; it ate away at me inside.

Q: You said you remembered the abuse throughout the years and recently connected it to your current symptoms in therapy. Tell me about that.

A: Through talking therapy, and relaxation, I became comfortable enough with Dr. Dunbar to disclose my horrible secret. For so long, I had blamed myself and felt ashamed and embarrassed for what he did to me. Dr. Dunbar helped me realize that in order to relieve my symptoms, I needed to face my fears and my past. We began to discuss the abuse and it was then, that I began to realize my depression and anxiety was the direct result of the abuse and keeping it hidden all these years.

Q: As painful as it is, can you please describe these memories of abuse for the jury. A: The summer of 1988, I stayed at my aunt and uncles during the weeks while my parents were at work. During this time, Uncle Robert would take me into the cabana by the swimming pool in the backyard and force me to remove my clothes. He would order me to perform oral sex on him and then would force me to have intercourse with him. He 
covered my mouth to prevent my screams of pain and after it was done, he made me get dressed and said if I ever told anyone, bad things would happen to my parents and I; that we would suffer. I never told a soul, not even my best friend.

Q. At any point during therapy, did Dr. Dunbar suggest your symptoms of depression and anxiety may have been the result of childhood sexual abuse?

A: No. Dr. Dunbar never once made any suggestions or accusations.

Q. When did the issue of sexual abuse arise in therapy?

A. We would frequently talk about past relationships and family, but I was afraid to bring up the abuse. Once I was comfortable with Dr. Dunbar, I disclosed my memories of sexual abuse to her. Only then did we begin to discuss the horrific memories and link them to my current problems. It was at that moment that I began to progress in therapy toward symptom relief, once I stopped blaming myself and feeling ashamed.

Q: How long would you say you have suffered the ramifications of the abuse committed against you by the defendant?

A: My whole life has been plagued by depression and distress. Even presently, I still suffer from residual symptoms of the abusive memories. The medical bills and therapy sessions are numerous and he (the defendant) is to blame. Through therapy, I have realized that I was a child then and it was not my fault. I am an adult now and not afraid to speak out anymore. He deserves to be punished for what he did to me. I was only a child, a defenseless child.

Mr. Morin: No further questions your honor.

\section{Cross-Examination of the Victim}

JUDGE: Mr. Dennehy (defense attorney), would you like to question the witness? 
Mr. Dennehy: Yes, thank you your honor.

Q: Good afternoon, Jennifer, I am Mr. Dennehy, the defense attorney in this case. I would like to ask you a few questions regarding your memories of abuse. When did you say you began attending therapy with Dr. Dunbar?

A: About one year ago.

Q: And how long into therapy were you before you disclosed your memories of abuse?

A: About 3 or 4 months in.

Q: Why had the memories not come up until this point?

A: As I said, I was not ready to share such painful memories and I was ashamed.

Q: Did Dr. Dunbar ever have you think back to childhood memories?

A: Yes. We would discuss my childhood and past often.

Q: Was there ever any suggestions made that your current symptoms seem compatible with those seen in abuse survivors?

A: No. Dr. Dunbar never suggested abuse. We merely talked about the past.

Q: How clear would you say the memories you have of the alleged abuse are?

A: I remember it as though it happened yesterday. I can still picture that cabana and how afraid I was every time I went to their house.

Q: Do you remember the exact dates the abuse occurred on?

A: No, just the summer of 1988 .

Q: Do remember the exact time of day the abuse occurred? Exactly what you were doing before and after?

A: Well, it was in the afternoon sometime... and no, I just remember his bringing me to the cabana. 
Q: Do you remember what you were doing on June 15, 2001?

A: Well, no not that exact date but I know what I did that summer.

Q: So it is fair to say that your memory of things is not exactly perfect?

A: Well, no, no one has a perfect memory.

Q: So, maybe your memories for the events that summer are less than perfect?

A: No. I know what happened that summer and he knows what happened that summer.

He abused me and I remember it clear as day because I replay it in my mind everyday since the times it happened. I was never the same after that summer.

Q: You have been experiencing psychological symptoms for a while Jennifer?

A: Yes, for as long as I can remember.

Q: And I certain that you would give anything to figure out the origin or cause of those symptoms, for relief?

A: Well, yes of course.

Q: Is it possible, that you wanted answers so badly that your mind created the memories of abuse as a way to cope with your symptoms?

A: No. That is not what happened. I have had these memories since I was 10 and they have not faded. Uncle Robert took my innocence. He abused me when I was just 10 years old and the truth will finally come out. I did not imagine this abuse and I did not make it up to fix my problems. This abuse caused my problems and I finally have the confidence to do something about it.

Mr. Dennehy: No further questions your honor.

Direct Examination of the Defense Expert

Q: Please state your name for the court. 
A: My name is Dr. William Springs.

Q: Dr. Springs, what are your qualifications for offering expert testimony on the psychology of memory?

A: I earned my undergraduate degree and went on to obtain a Ph.D. in psychology. I have conducted scientific research on human memory including short and long term memory, suggestibility, and false memory for over 20 years. I have authored 9 book chapters and approximately 50 scientific articles on memory and an additional 15 articles concerning psychological distress and suggestibility. I have taught many undergraduate and graduate psychology courses and have over 25 years practical experience. I have also served as an expert witness in over 45 trials.

Q: Dr. Springs, tell us how human memory works.

A: Human memory is a complex cognitive process involving three distinct stages. At the first stage, information is perceived and encoded into memory. At the second stage, encoded information is stored in memory. At the third stage, stored information is retrieved from memory, such as when a witness is asked to recall information about a crime. Memory is vulnerable at each of these stages. There are factors that can influence what information a witness or victim perceives or encodes into memory. There are factors that can influence the accuracy of memories.

Q: In your experience as a researcher and clinician, how accurate do believe memory to be after long periods of time?

A: Memory can be both unreliable and in accurate at times. Research has demonstrated that we construct our memories after the fact and that we are susceptible to suggestions from others that help us fill in the gaps of our memories. It is possible to create false 
memories in an individual's mind by suggestion, even false memories of supposed previous lives.

Q: Should memories of an event be taken at face value with no other corroborating evidence?

A: Memory is so malleable that we should be very cautious in claiming certainty about any given memory without corroborative evidence.

Q: Can you go into more detail about that Dr. Springs.

A: Well, human memory is greatly influenced by expectations and when memories are incomplete, people have a tendency to fill in the gaps by creating images of what they believe or someone else believes must have happened or should have happened. If an individual alleges to have a traumatic memory, such as child abuse, and is currently experiencing psychological distress, they may come to believe they experienced things that may have never happened as a way of explaining and coping with their current mental health deterioration.

Q: Do you believe it is possible for a therapist, either intentionally or unintentionally, to suggest to a client that their symptoms of distress may have been caused by some sort of traumatic childhood experience?

A: Clients entering therapy to deal with depression or anxiety, often long for some sort of explanation for their current state. The therapist may see their symptoms as fitting into some predetermined profile of an abuse survivor, alcohol, etc. The client, desperately seeking relief from their problems, may fill in gaps of childhood with memories that "make sense" and could have caused their current state. If a client shares these thoughts 
with the therapist, who may have already had a preconceived notion, the therapist may encourage the client to explore the memories in order to relieve symptoms.

Q: Can these memories become real and vivid in the eyes of the client, even if they had not occurred?

A: Yes. Vivid and detailed memory may be based upon such an inaccurate reconstruction of facts, or largely self-created impressions that appear to have actually occurred. Things such as someone helping you get changed as a child, may turn into well I think he used to touch me when I changed, to I was sexually abused and that is what caused my problems. Q: Do you have anything else to add, Dr. Springs?

A: Well, memory is a reconstructed phenomenon, and so it can often be strongly influenced by various biases, such as subjective or social expectations, emotions, the implied beliefs of others, inappropriate interpretations, or desired outcomes.

Psychological distress not only can distort memories, but also result in an individual believing something may have happened when it in fact did not. Especially when so much time has passed between an original memory and recalling the memory. It is easy for distortions to take place.

Mr. Dennehy: Thank you Dr. Springs. I have no further questions your honor.

\section{Cross-Examination of Defense Expert}

JUDGE: Mr. Morin, would you like to question the witness?

Mr. Morin: Yes, thank you, your honor.

Q: Dr. Springs, you say that you have testified as an expert in how many trials?

A: Approximately 45 or so. 
Q: And of these 45 or so trials, how many times have you testified on behalf of the prosecution?

A: I have never testified on behalf of the prosecution.

Q: So it would seem you solely testify on behalf of the defense?

A: Yes, I suppose that would be true.

Q: Was there ever a time when you testified in defense of a defendant on trial for sexual abuse that was proven guilty without a doubt?

A: Yes, I believe that I have.

Q: So it seems you will testify as an expert for the defense no matter what the circumstances?

A: Well, I wouldn't say that but...

Q: Yes or no, Dr. Springs.

A: Well, yes I only have testified for the defense.

Q: Now, you base most of your claims about memories off the research in that area?

A: Yes, that is correct; my research and the research others in the field.

Q: And what have you found?

A: That memory is malleable and can change over time. Also, that memory can be altered by suggestions to an individual. The individual will sometimes embrace a suggestion and incorporate it into the original memory, even if the suggestion was inaccurate. Also, we have found that memory is not always reliable.

Q: In your research, have you suggested to participants that they had been sexually abused as a child and they later recollected this suggestion? 
A: No, there are no studies to my knowledge that suggest an individual was abused. That would be unethical. We may show a video or a picture and make a subtle suggestion about the clothing an individual wore or a certain sign in the video being something other than it was.

Q: Yet, you generalize this research to therapists suggesting sexual abuse to a client and the client claiming they were abused as a child as a result of the therapist's suggestion? A: Well the results are meant to show that individual's are suggestible. Q: Are the participants in your studies suffering from current psychological symptoms such as depression and anxiety, when you make such suggestions?

A: We do not measure psychological distress in our studies, so I am unsure.

Q: Do you believe that someone can be abused and never talk about it?

A: Well, yes I think that is possible.

Q: And that they can know they were abused and remember they were abused, but not tell anyone for many years?

A: Yes... I think that could happen.

Q: So then it is possible that Jennifer was abused as a child and never told anyone, until she entered therapy for her distress?

A: Well... yes I guess it is possible. Her memories for the events of the abuse, however, may not be accurate.

Q: But it is possible, Dr. Springs, that Jennifer was abused 20 years ago and never told anyone until she recalled the memories of abuse to her therapist?

A: Yes, it is possible. 
Q: And though you said individual memory is suggestible, it is possible for people to remember events and experiences without suggestion?

A: Yes, it is possible.

Q: And are you aware that Dr. Dunbar (Jennifer's therapist) did not make any suggestions to Jennifer in therapy regarding childhood sexual abuse?

A: Yes, I am aware of this.

Q: So is it possible that Jennifer disclosed the memories of abuse for the first time in 20 years to her therapist under no suggestion or contamination?

A: Well, yes, I guess it is possible.

Mr. Morin: No further questions your honor.

Condition 8: No Hypnosis/Both Experts

Direct Examination of the Victim

JUDGE: Today we are hearing evidence in the case of Jennifer Riley v. Robert Smith.

The defendant, Mr. Smith is accused of sexually abusing the Plaintiff, Ms. Riley, 20

years prior to this trial. Mr. Morin (plaintiff's attorney) would you like to call your first witness?

A: Yes, your honor. I would like to call Jennifer Riley to the stand.

OATH: Do you solemnly swear you will tell the truth and nothing but the truth, so help you?

A: Yes.

Q: Please state your full name?

A: My name is Jennifer Riley. 
Q: What brings you to court today Jennifer?

A: I am filing suit for damages endured as a result of repeated sexual abuse.

Q: When did this abuse occur Jennifer?

A: Twenty years ago when I was 10 years old.

Q: Who is the person that abused you when you were such a young child?

A: That man (points to the defendant), my uncle Robert.

Q: And why did it take 20 years for you to file charges against Robert?

A: I have carried the memories of the abuse with me since I was a child. My uncle threatened me back then that if I ever told anyone, my parents and I would suffer for it. In the last year or so, I have been regularly attending therapy with Dr. Dietz to treat depression and anxiety. I have had these symptoms for as long as I can remember. Therapy was the first time I disclosed the abuse to another person and began to discover that my current depression and anxiety could be the result of residual distress from the abuse I kept hidden so many years.

Q: You attended therapy to treat depression and anxiety, Jennifer. Tell me about that. A: For as long as I can remember, I have experienced intense psychological symptoms of depression and anxiety. The depression and distress has been so severe that it has affected my work, intimate and personal relationships, and everyday life. Some days are so bad I cannot even get out of bed. My distrust of others has prevented any sort of long-term relationships and there are times when I feel completely hopeless and helpless. I kept the abuse hidden for so long; it ate away at me inside.

Q: You said you remembered the abuse throughout the years and recently connected it to your current symptoms in therapy. Tell me about that. 
A: Through talking therapy, and relaxation, I became comfortable enough with Dr. Dunbar to disclose my horrible secret. For so long, I had blamed myself and felt ashamed and embarrassed for what he did to me. Dr. Dunbar helped me realize that in order to relieve my symptoms, I needed to face my fears and my past. We began to discuss the abuse and it was then, that I began to realize my depression and anxiety was the direct result of the abuse and keeping it hidden all these years.

Q: As painful as it is, can you please describe these memories of abuse for the jury.

A: The summer of 1988, I stayed at my aunt and uncles during the weeks while my parents were at work. During this time, Uncle Robert would take me into the cabana by the swimming pool in the backyard and force me to remove my clothes. He would order me to perform oral sex on him and then would force me to have intercourse with him. He covered my mouth to prevent my screams of pain and after it was done, he made me get dressed and said if I ever told anyone, bad things would happen to my parents and I; that we would suffer. I never told a soul, not even my best friend.

Q. At any point during therapy, did Dr. Dunbar suggest your symptoms of depression and anxiety may have been the result of childhood sexual abuse?

A: No. Dr. Dunbar never once made any suggestions or accusations.

Q. When did the issue of sexual abuse arise in therapy?

A. We would frequently talk about past relationships and family, but I was afraid to bring up the abuse. Once I was comfortable with Dr. Dunbar, I disclosed my memories of sexual abuse to her. Only then did we begin to discuss the horrific memories and link them to my current problems. It was at that moment that I began to progress in therapy toward symptom relief, once I stopped blaming myself and feeling ashamed. 
Q: How long would you say you have suffered the ramifications of the abuse committed against you by the defendant?

A: My whole life has been plagued by depression and distress. Even presently, I still suffer from residual symptoms of the abusive memories. The medical bills and therapy sessions are numerous and he (the defendant) is to blame. Through therapy, I have realized that I was a child then and it was not my fault. I am an adult now and not afraid to speak out anymore. He deserves to be punished for what he did to me. I was only a child, a defenseless child.

Mr. Morin: No further questions your honor.

\section{Cross-Examination of the Victim}

JUDGE: Mr. Dennehy (defense attorney), would you like to question the witness? Mr. Dennehy: Yes, thank you your honor.

Q: Good afternoon, Jennifer, I am Mr. Dennehy, the defense attorney in this case. I would like to ask you a few questions regarding your memories of abuse. When did you say you began attending therapy with Dr. Dunbar?

A: About one year ago.

Q: And how long into therapy were you before you disclosed your memories of abuse?

A: About 3 or 4 months in.

Q: Why had the memories not come up until this point?

A: As I said, I was not ready to share such painful memories and I was ashamed.

Q: Did Dr. Dunbar ever have you think back to childhood memories?

A: Yes. We would discuss my childhood and past often. 
Q: Was there ever any suggestions made that your current symptoms seem compatible with those seen in abuse survivors?

A: No. Dr. Dunbar never suggested abuse. We merely talked about the past.

Q: How clear would you say the memories you have of the alleged abuse are?

A: I remember it as though it happened yesterday. I can still picture that cabana and how afraid I was every time I went to their house.

Q: Do you remember the exact dates the abuse occurred on?

A: No, just the summer of 1988 .

Q: Do remember the exact time of day the abuse occurred? Exactly what you were doing before and after?

A: Well, it was in the afternoon sometime... and no, I just remember his bringing me to the cabana.

Q: Do you remember what you were doing on June 15, 2001 ?

A: Well, no not that exact date but I know what I did that summer.

Q: So it is fair to say that your memory of things is not exactly perfect?

A: Well, no, no one has a perfect memory.

Q: So, maybe your memories for the events that summer are less than perfect?

A: No. I know what happened that summer and he knows what happened that summer.

He abused me and I remember it clear as day because I replay it in my mind everyday since the times it happened. I was never the same after that summer.

Q: You have been experiencing psychological symptoms for a while Jennifer? A: Yes, for as long as I can remember. 
Q: And I certain that you would give anything to figure out the origin or cause of those symptoms, for relief?

A: Well, yes of course.

Q: Is it possible, that you wanted answers so badly that your mind created the memories of abuse as a way to cope with your symptoms?

A: No. That is not what happened. I have had these memories since I was 10 and they have not faded. Uncle Robert took my innocence. He abused me when I was just 10 years old and the truth will finally come out. I did not imagine this abuse and I did not make it up to fix my problems. This abuse caused my problems and I finally have the confidence to do something about it.

Mr. Dennehy: No further questions your honor.

Direct Examination of Plaintiff Expert

Q: Please state your name for the court.

A: My name is Dr. Rachel Dunbar.

Q: Dr. Dunbar, would you please describe your credentials for the court?

A: I earned my undergraduate degree at State University and then earned a Ph. D. in clinical psychology. I am a clinician and researcher specializing in human memory and counseling. I have over 25 years of practical experience and have taught numerous courses at the undergraduate and graduate level. I am a member of the American Psychological Association author of 15 books, 9 book chapters, and over 50 articles for prestigious psychological journals. I have presented research at over 15 conferences and both attend and conduct lectures on clinical research and practice.

Q: Was Jennifer Riley one of your clients in therapy? 
A: Jennifer came to my office seeking therapy for a number of reasons. She was suffering from long-term depression and anxiety. She was having trouble sleeping, eating, at work, at home, and in her relationships.

Q: About how far into therapy were you before Jennifer disclosed her memories of abuse?

A: About 3 or 4 months into therapy. Jennifer was reserved at the start of therapy and appeared unsure of herself and ashamed of her depression. I did my best to build rapport and make her feel as comfortable as possible in my office. We discussed her past relationships and childhood memories. It seemed that when she was comfortable, Jennifer told me about the abuse she endured 20 years earlier.

Q: Dr. Dunbar, you said you specialize in memory and counseling. Tell the court more about human memory.

A: Memory is the retention of, and ability to recall, information, personal experiences, procedures, etc. Research on memory and neuroscience demonstrates support for the notion that a memory is a set of encoded neural connections. Encoding can take place in several parts of the brain, and thus, these neural connections can take place in several parts of the brain. The stronger these connections, the stronger the memory. Q: And what about memory recollection?

A: Recollection of an event can occur by a stimulus to any of the parts of the brain where a neural connection for the memory occurs. If a part of the brain is damaged, access to any neural data that was there is lost. On the other hand, if the brain is healthy and a person is fully conscious when experiencing some trauma, the likelihood that they will 
forget the event is nearly zero, unless they either are very young or experienced a brain injury.

Q: Is it possible that Jennifer experienced sexual abuse at the age of 10, never told anyone, and still clearly remembers the events today 20 years later?

A: Since Jennifer ascertains that the abuse occurred at 10 years old, it is possible that she formed long lasting memories of the experience and has remembered the abuse throughout the years, even if she did not discuss it with anyone until therapy. Q: Do you believe traumatic memories are harder to forget?

A: I support the claim that the more traumatic an experience, the more likely an individual is to remember it. Novel visual images, which would frequently accompany traumatic experiences, stimulate the hippocampus and left inferior prefrontal cortex and generally become part of long-term memory.

Q: Did you, at any point in time, suggest to Jennifer that she had been sexually abused as a child?

A: No, I did not make any such suggestions.

Q: Did you ever suggest to Jennifer that her symptoms may be linked to or resulted from sexual abuse of any kind?

A: No, I did not. I have seen clients like Jennifer who are survivors of sexual abuse presenting with similar symptoms; however, I never once suggested to Jennifer that her symptoms must have been the result of such abuse.

Q: Do you believe that traumatic experiences such as childhood sexual abuse can cause psychological distress in adulthood similar to Jennifer's problems? 
A: Yes, I do. When traumatic experiences occur in childhood they can cause immense psychological distress throughout the victim's life and into adulthood, even more so if the victim kept the experiences hidden from family members and friends. Childhood sexual abuse can cause problems with intimate relationships, work, daily life, and can result in the victim being ashamed, anxious, and depressed. Child victims tend to blame themselves for the abuse and carry this shame into adulthood, worsening their psychological trauma.

Q: Is it possible that Jennifer is experiencing depression and anxiety as a result of the sexual abuse she endured 20 years ago?

A: Yes, in my opinion it is definitely possible that the traumatic experiences of Jennifer's childhood have permeated her psychological well being and caused her symptoms.

Q: Dr. Dunbar, do you believe that Jennifer's memories of abuse represent the true state of affairs and can be considered credible?

A: It is my opinion that Jennifer's memories are both accurate and credible, and that her symptoms could be seen as a direct result of such memories and traumatic experiences. Mr. Morin: Thank you. No further questions your honor. Cross-Examination of Plaintiff Expert

JUDGE: Mr. Dennehy, would you like to question the witness?

Mr. Dennehy: Yes, thank you, your honor.

Q: Dr. Dunbar, you mentioned that Jennifer's symptoms fit the profile of an adult that had been sexually abused as a child?

A: Yes, I believe I said something like that. 
Q: Would you say you spent a considerable amount of time talking about Jennifer's past relationships and childhood?

A: Well, yes, we explored Jennifer's life history and her childhood frequently in the beginning of therapy.

Q: Did you ever think that repetitively talking about childhood, may have suggested to Jennifer that her problems originated in childhood?

A: No... Lengthy discussions about the client's life are all part of building rapport and making the client comfortable. I never once suggested her psychological issues originated in childhood; thus, I would not think I led Jennifer to believe I expected anything from her.

Q: How long have you practiced as a clinician, Dr. Dunbar?

A: For over 25 years.

Q: And in those 25 years have you ever made suggestions to a client as to the origins of their psychological distress?

A: Well, there are different types of suggestions...

Q: Yes or no Doctor?

A: Yes.

Q: Is it possible that you may have made some sort of comment of suggestion to Jennifer during therapy that led her to believe her symptoms were the result of sexual abuse as a child?

A: No, no such comment was made. I did not make any suggestions to Jennifer that she had been abused.

Q: Now Dr. Dunbar, are you aware of the research regarding memory and recollection? 
A: Well, of course. I specialize in that area.

Q: Are you aware of studies demonstrating the unreliability and inaccuracy of memory?

A: Well, yes... no individual has a perfect memory.

Q: Are you aware of the research demonstrating that individuals construct memories after the fact and are susceptible to the suggestions from others to fill in gaps of the memory? A: Well that is one side of memory. I am also aware of the research demonstrating that after many years memories can remain intact and accurate.

Q: Is it possible that in a high state of psychological distress, an individual's original memory may become distorted?

A: Well, yes... I suppose that is possible.

Q: And would you say Jennifer was in a high state of distress when she came to you for therapy?

A: Well of course, she was suffering from anxiety and depression.

Dr. Dennehy: No further questions your honor.

Direct Examination of the Defense Expert

Q: Please state your name for the court.

A: My name is Dr. William Springs.

Q: Dr. Springs, what are your qualifications for offering expert testimony on the psychology of memory?

A: I earned my undergraduate degree and went on to obtain a Ph.D. in psychology. I have conducted scientific research on human memory including short and long term memory, suggestibility, and false memory for over 20 years. I have authored 9 book chapters and approximately 50 scientific articles on memory and an additional 15 articles concerning 
psychological distress and suggestibility. I have taught many undergraduate and graduate psychology courses and have over 25 years practical experience. I have also served as an expert witness in over 45 trials.

Q: Dr. Springs, tell us how human memory works.

A: Human memory is a complex cognitive process involving three distinct stages. At the first stage, information is perceived and encoded into memory. At the second stage, encoded information is stored in memory. At the third stage, stored information is retrieved from memory, such as when a witness is asked to recall information about a crime. Memory is vulnerable at each of these stages. There are factors that can influence what information a witness or victim perceives or encodes into memory. There are factors that can influence the accuracy of memories.

Q: In your experience as a researcher and clinician, how accurate do believe memory to be after long periods of time?

A: Memory can be both unreliable and in accurate at times. Research has demonstrated that we construct our memories after the fact and that we are susceptible to suggestions from others that help us fill in the gaps of our memories. It is possible to create false memories in an individual's mind by suggestion, even false memories of supposed previous lives.

Q: Should memories of an event be taken at face value with no other corroborating evidence?

A: Memory is so malleable that we should be very cautious in claiming certainty about any given memory without corroborative evidence. Q: Can you go into more detail about that Dr. Springs. 
A: Well, human memory is greatly influenced by expectations and when memories are incomplete, people have a tendency to fill in the gaps by creating images of what they believe or someone else believes must have happened or should have happened. If an individual alleges to have a traumatic memory, such as child abuse, and is currently experiencing psychological distress, they may come to believe they experienced things that may have never happened as a way of explaining and coping with their current mental health deterioration.

Q: Do you believe it is possible for a therapist, either intentionally or unintentionally, to suggest to a client that some sort of traumatic childhood experience may have caused their symptoms of distress?

A: Clients entering therapy to deal with depression or anxiety, often long for some sort of explanation for their current state. The therapist may see their symptoms as fitting into some predetermined profile of an abuse survivor, alcohol, etc. The client, desperately seeking relief from their problems, may fill in gaps of childhood with memories that "make sense" and could have caused their current state. If a client shares these thoughts with the therapist, who may have already had a preconceived notion, the therapist may encourage the client to explore the memories in order to relieve symptoms.

Q: Can these memories become real and vivid in the eyes of the client, even if they had not occurred?

A: Yes. Vivid and detailed memory may be based upon such an inaccurate reconstruction of facts, or largely self-created impressions that appear to have actually occurred. Things such as someone helping you get changed as a child, may turn into well I think he used to touch me when I changed, to I was sexually abused and that is what caused my problems. 
Q: Do you have anything else to add, Dr. Springs?

A: Well, memory is a reconstructed phenomenon, and so it can often be strongly influenced by various biases, such as subjective or social expectations, emotions, the implied beliefs of others, inappropriate interpretations, or desired outcomes. Psychological distress not only can distort memories, but also result in an individual believing something may have happened when it in fact did not. Especially when so much time has passed between an original memory and recalling the memory. It is easy for distortions to take place.

Mr. Dennehy: Thank you Dr. Springs. I have no further questions your honor.

\section{Cross-Examination of Defense Expert}

JUDGE: Mr. Morin, would you like to question the witness?

Mr. Morin: Yes, thank you, your honor.

Q: Dr. Springs, you say that you have testified as an expert in how many trials?

A: Approximately 45 or so.

Q: And of these 45 or so trials, how many times have you testified on behalf of the prosecution?

A: I have never testified on behalf of the prosecution.

Q: So it would seem you solely testify on behalf of the defense?

A: Yes, I suppose that would be true.

Q: Was there ever a time when you testified in defense of a defendant on trial for sexual abuse that was proven guilty without a doubt?

A: Yes, I believe that I have. 
Q: So it seems you will testify as an expert for the defense no matter what the circumstances?

A: Well, I wouldn't say that but...

Q: Yes or no, Dr. Springs.

A: Well, yes I only have testified for the defense.

Q: Now, you base most of your claims about memories off the research in that area?

A: Yes, that is correct; my research and the research others in the field.

Q: And what have you found?

A: That memory is malleable and can change over time. Also, that memory can be altered by suggestions to an individual. The individual will sometimes embrace a suggestion and incorporate it into the original memory, even if the suggestion was inaccurate. Also, we have found that memory is not always reliable.

Q: In your research, have you suggested to participants that they had been sexually abused as a child and they later recollected this suggestion?

A: No, there are no studies to my knowledge that suggest an individual was abused. That would be unethical. We may show a video or a picture and make a subtle suggestion about the clothing an individual wore or a certain sign in the video being something other than it was.

Q: Yet, you generalize this research to therapists suggesting sexual abuse to a client and the client claiming they were abused as a child as a result of the therapist's suggestion? A: Well the results are meant to show that individual's are suggestible. Q: Are the participants in your studies suffering from current psychological symptoms such as depression and anxiety, when you make such suggestions? 
A: We do not measure psychological distress in our studies, so I am unsure.

Q: Do you believe that someone can be abused and never talk about it?

A: Well, yes I think that is possible.

Q: And that they can know they were abused and remember they were abused, but not tell anyone for many years?

A: Yes... I think that could happen.

Q: So then it is possible that Jennifer was abused as a child and never told anyone, until she entered therapy for her distress?

A: Well... yes I guess it is possible. Her memories for the events of the abuse, however, may not be accurate.

Q: But it is possible, Dr. Springs, that Jennifer was abused 20 years ago and never told anyone until she recalled the memories of abuse to her therapist?

A: Yes, it is possible.

Q: And though you said individual memory is suggestible, it is possible for people to remember events and experiences without suggestion?

A: Yes, it is possible.

Q: And are you aware that Dr. Dunbar (Jennifer's therapist) did not make any suggestions to Jennifer in therapy regarding childhood sexual abuse?

A: Yes, I am aware of this.

Q: So is it possible that Jennifer disclosed the memories of abuse for the first time in 20 years to her therapist under no suggestion or contamination?

A: Well, yes, I guess it is possible.

Mr. Morin: No further questions your honor. 


\section{Instructions}

Members of the jury, I thank you for your attention. Please pay attention to the following instructions.

\section{STATEMENT OF CHARGE}

Robert Smith, the defendant in this case, has been accused of sexual abuse against the Plaintiff, Jennifer Riley.

\section{PLEA OF NOT GUILTY; CLEAR AND CONVINCING EVIDENCE; AND BURDEN}

\section{OF PROOF}

The defendant has entered a plea of not guilty. This means you must presume or believe the defendant is innocent. The presumption stays with the defendant as to each material allegation in the information through each stage of the trial until it has been overcome by the evidence to the exclusion beyond clear and convincing evidence.

The defendant is not required to prove anything.

Whenever the words "clear and convincing evidence" are used you must consider the following:

To prove something by "clear and convincing evidence", the party with the burden of proof must convince the trier of fact that it is substantially more likely than not that the thing is in fact true.

In civil law cases, the "burden of proof" requires the plaintiff to convince the trier of fact (whether judge or jury) of the plaintiff's entitlement to the relief sought. This means that the plaintiff must prove each element of the claim, or cause of action, in order to recover. It is to the evidence introduced upon this trial, and to it alone, that you are to look for that proof. 
If you think it is substantially more than likely that the thing the defendant is being charged with is in fact true, you should find the defendant liable/culpable.

If you do not think is substantially more than likely that the thing is in fact true, then you should find the defendant not liable/not culpable.

\section{WEIGHING THE EVIDENCE}

It is up to you to decide what evidence is reliable. You should use your common sense in deciding which is the best evidence, and which evidence should not be relied upon in considering your verdict. You may find some of the evidence is not reliable, or less reliable than other evidence.

You should consider what each witness said. Some things you should consider are:

1. Did the witness seem to have an opportunity to see and know the things about which they testified?

2. Did the witness seem to have an accurate memory?

3. Was the witness honest and straightforward in answering questions?

4. Does the witness testimony agree with the other testimony and evidence in this case?

5. Was the witness consistent in his/her testimony?

You may rely upon your own conclusion about the witness. A jury may believe or disbelieve all or any part of the evidence or testimony of any witness.

You may or may not have heard testimony from an expert witness(es) who, because of education or experience, are permitted to state expert opinions and the reasons for their opinions. Opinion testimony should be judged just like any other testimony. You 
may accept it, or reject it, and give as much weight as you think it deserves, considering the witness' education and experience, the reason given for the opinion, and all other evidence in the case.

\section{DEFENDANT NOT TESTIFYING}

The constitution requires the Plaintiff to prove its accusations against the defendant in this case. It is not necessary for the defendant to disprove anything. Nor is the defendant required to prove his innocence. It is up to the Plaintiff to prove the defendant's culpability by evidence.

The defendant exercised a fundamental right by choosing not to be a witness in this case. You must not view this as an admission of liability or be influenced in any way by this decision. No juror should ever be concerned that the defendant did or did not take the witness stand to give testimony in this case.

\section{SUBMITTING CASE TO JURY}

In closing, let me remind you that it is important that you follow the law spelled out in these instructions in deciding your verdict. Even if you do not like the laws that must be applied, you must use them. We have agreed to a constitution and to live by the law. No one of us has the right to violate rules we all share. Thank you. 


\section{Verdict Assessment}

As a juror in this case, the judge has instructed you to use the "clear and convincing evidence" standard-of-proof to make your verdict decision. Please circle the number that corresponds to how culpable you feel the defendant is for sexually abusing the victim.

1 2

Not at all Culpable

How confident are you of this assessment?

1

2

3

4

Not at all Confident
4

5

Completely Culpable 6 


\section{Credibility of Victim}

For each of the following statements, please circle the number that best reflects your opinion.

How credible do you find the victim's testimony alleging the defendant sexually abused her in this case?
1
2
3
4
5
6

Not at all Credible

Entirely Credible

How believable did you find the victim's testimony alleging the defendant sexually abused her in this case?
1
2
3
4
5
6

Not at all Believable

Entirely Believable

How accurate do you find the victim's memories of childhood sexual abuse?
1
2
3
4
5
6

Not at all Accurate

Entirely Accurate

Did you think the victim was honest?

1 2

3

4

5 6

Not al all Honest

Completely Honest

How trustworthy was the victim in this case?
1
2
3
4
5
6

Not at all Trustworthy

Very Trustworthy

Did you think the victim's testimony was consistent?

1 2

$2 \quad 3 \quad 4$

$2 \quad 3 \quad 4$

Not at all Consistent
5

6

Very Consistent 
Understanding 133

To what extent did the victim's testimony influence your verdict decision?

1

Did Not Influence
3

2

4

5

Greatly Influenced 


\section{Expert Testimony}

For each of the following statements, please circle the number that best reflects your opinion.

How credible did you find the expert witness testimony in this case?

$\begin{array}{llllll}1 & 2 & 3 & 4 & 5 & 6\end{array}$

Not at all Credible

Entirely Credible

How believable did you find the expert witness testimony in this case?
1
2
3
4
5
6

Not at all Believable

Entirely Believable

How trustworthy was the expert witness in this case?
1
2
3
4
5
6

Not at all Trustworthy

Very Trustworthy

Did you think the expert testimony was consistent?
1
2
3
4
5
6

Not at all Consistent

Very Consistent

To what extent did the expert witness testimony influence your views of the victim's credibility?
1
2
3
4
5
6

Did Not Influence

Greatly Influenced

To what extent did the presence of expert witness testimony influence your verdict decision?
1
2
3
4
5
6

Did Not Influence

Greatly Influenced 
To what extent did the expert witness testifying in favor of the victim influence your verdict decision?
1
3
4
5
6

Did Not Influence

Greatly Influenced

To what extent did the expert witness testifying on behalf of the defendant influence your verdict decision?
1
2
3
4
5
6

Did Not Influence

Greatly Influenced

To what extent did the expert witness testimony in favor of the victim influence your views of the victim's credibility?
1
2
3
4
5
6

Did Not Influence

Greatly Influenced

To what extent did the expert witness testimony in favor of the defendant influence your views of the victim's credibility?
1
2
3
4
5
6

Did Not Influence

Greatly Influenced

How strong was the plaintiff's case against the defendant?
1
2
3
4
5
6

Very Weak

Very strong

How strong was the defenses case against the victim?

$\begin{array}{llllll}1 & 2 & 3 & 4 & 5 & 6\end{array}$

Very Weak

Very strong 
Debriefing

\section{Debriefing Statement}

I appreciate your participation in my study on juror perceptions. The responses you provided will be used to examine effects of hypnotically-induced testimony on witness credibility and verdict outcomes in civil suits involving claims of childhood sexual abuse. Further, your responses will also be used to examine the effects of expert witness testimony on juror perceptions of witness credibility and verdict outcome, along with how attitudes toward the victim and hypnotically-refreshed testimony may also influence witness credibility and juror decision making.

If you have any concerns regarding this study or would like to inquire about the outcome of the study, please feel free to contact Samantha Fusco via email: sfusco036@hawks.rwu.edu or telephone: 774-239-4141 or Judith Platania via email: jplatania@rwu.edu. Thank you for your participation. 